\title{
AVALIAÇÃO DA RESISTÊNCIA À TRAÇÃO DE UMA RESINA COMPOSTA FOTOPOLIMERIZÁVEL EM FUNÇÃO DE DIFERENTES FONTES DE LUZ E DE TEMPOS DE ATIVAÇÃO
}

\section{VIRGINIA BOSQUIROLI}

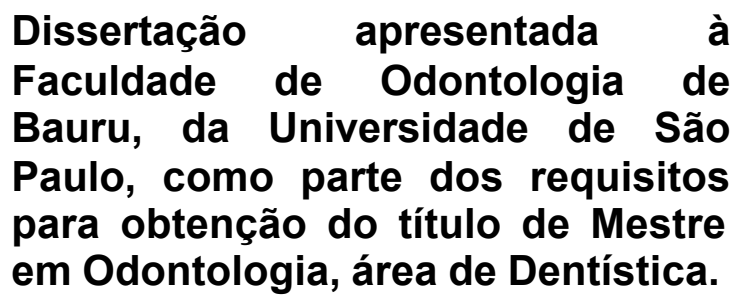

(Edição Revisada)

\section{BAURU}

2003 


\title{
AVALIAÇÃO DA RESISTÊNCIA À TRAÇÃO DE UMA RESINA COMPOSTA FOTOPOLIMERIZÁVEL EM FUNÇÃO DE DIFERENTES FONTES DE LUZ E DE TEMPOS DE ATIVAÇÃO
}

\section{VIRGINIA BOSQUIROLI}

\begin{abstract}
Dissertação apresentada à Faculdade de Odontologia de Bauru, da Universidade de São Paulo, como parte dos requisitos para obtenção do título de Mestre em Odontologia, área de Dentística.
\end{abstract}

(Edição Revisada)

Orientador: Prof. Dr. Eduardo Batista Franco

BAURU

2003 
Bosquiroli, Virginia

B652a Avaliação da resistência à tração de uma resina composta fotopolimerizável em função de diferentes fontes de luz e de tempos de ativação / Virginia Bosquiroli. - Bauru, 2003.

109p. : il. ; 30cm

Dissertação (Mestrado) - Faculdade de Odontologia de Bauru. USP

Orientador: Prof. Dr. Eduardo Batista Franco

Autorizo, exclusivamente para fins acadêmicos e científicos, a reprodução total ou parcial desta dissertação, por processos fotocopiadores e/ou meios eletrônicos.

Assinatura do autor (a):

Data: 


\section{VIRGINIA BOSQUIROLI}

Filiação

Nascimento

Naturalidade

1988 a 1993

1994

1996 a 1997

1998

1999

Associações
Ivo José Bosquiroli

Eugênia lark Bosquiroli

27 de novembro de 1970

Cascavel-PR

Curso de Odontologia na Faculdade de Odontologia de Passo Fundo - RS.

Curso de Pós-graduação em Odontopediatria, nível de Aperfeiçoamento, na Escola de Aperfeiçoamento Profissional da Associação Brasileira de Odontologia de Curitiba - PR Curso de Pós-graduação em Dentística Restauradora, nível de Especialização, na Escola de Aperfeiçoamento Profissional da Associação Brasileira de Odontologia de Ponta Grossa - PR.

Início Carreira Docente no Curso de Odontologia da UNIOESTE - Universidade Estadual do Oeste do Paraná.

Início de Docência no Curso de Aperfeiçoamento Profissional em Odontologia Estética e Adesiva na Escola de Aperfeiçoamento Profissional da Associação Brasileira de Odontologia de subseção de Cascavel - PR.

ABO - Associação Brasileira de Odontologia, subsecção Cascavel-PR

GBPD - Grupo Brasileiro de Professores de Dentística

SBPqO - Sociedade Brasileira de Pesquisa Odontológica

IADR - International Association for Dental Research 
"Assim como a semente traça a forma e o destino da árvore, os teus próprios desejos é que te configuram a vida."

\section{Francisco Cândido Xavier}


Dedico esta vitória aos meus pais

Eugênia e Ivo, exemplos de caráter, perseverança e amor incondicional. Obrigada pela presença constante, presença que sempre me incentiva a superar os obstáculos e a lutar pela vida com muito trabalho e sabedoria.

A vocês, meu intenso amor, reconhecimento e gratidão. 
A Deus, pelo dom da vida e pela constante proteção de Pai. Agradeço por estar aqui e por todas as oportunidades de crescimento e realizações que tens designado para minha vida.

Aos meus irmãos, Paulo, Ivânia, Giovana e Cristine, porque sempre me apoiaram e porque acima de tudo, o amor que nos une é muito especial.

Aos meus cunhados e amigos, Maria Beatriz, Vitor Hugo e Paulo pelo incentivo e porque sempre procuram estar presentes.

Aos meus sobrinhos(as) Ivan, Ana Paula e às princesinhas Thaísa e Elisa, pelo nosso convívio em família tão cheio de amor que alegra nossos dias.

A minha amiga Adriane Paglia, pelo incentivo aos meus estudos na Dentística e na minha carreira profissional. Pela motivação nos momentos mais difíceis, pela nossa bela amizade. 
Agradecimento Especial

Ao Professor Doutor Eduardo Batista Franco, pela experiência e conhecimentos adquiridos durante sua cuidadosa orientação em todas as etapas desta pesquisa e em todas as atividades que desenvolvi neste mestrado. O seu perfil profissional e ético de dedicação e compromisso com o ensino e a verdade científica mostrou-me também um exemplo a ser seguido na carreira docente.

"Mais do que compartilhar um conjunto de fatos e informações, o ensino verdadeiro é a influência de uma personalidade sobre a outra".

Frank E. Gaebelein 
À Professora Doutora Maria Fidela de Lima Navarro, pela coordenação deste Mestrado, pela honra de ter convivido com seu exemplo de determinação, dedicação profissional e, sobretudo pelo exemplo de vida.

Ao Professor Doutor Newton de Moraes, porque além de ter lutado pelo Mestrado Interinstitucional foi nosso incentivador constante e amigo. Obrigada por construir esta oportunidade.

Ao Professor Doutor José Mondelli, pela experiência transmitida de forma humilde com a qual presenteia os de seu convívio. Porque é motivo de muito orgulho ter conhecido o seu trabalho de perto. Uma vida de encantadora dedicação à Odontologia.

Ao Professor Doutor José Carlos Pereira, por todo conhecimento transmitido com tanta dedicação e paciência. Sempre admirarei seu dom para o ensino e o compromisso que assume com a pesquisa. Pelo incentivo e amizade.

Ao Professor Doutor Ricardo Marins de Carvalho, pelos conhecimentos transmitidos e pela atenção prestada sempre que precisei. Pela oportunidade de observar a sua impecável capacidade e dedicação ao ensino e à pesquisa. 
Aos professores do Departamento de Dentística, Aquira Ishikiriama, Carlos Eduardo Francischone, Rafael Francisco Lia Mondelli, Mário Honorato Silva e Souza Jr, Maria Tereza Atta Alves Bastos pelo privilégio de através de vossos ensinamentos, adquirir conhecimento científico e realizar o sonho de estudar nesta exemplar instituição de ensino.

A todos os professores da Faculdade de Odontologia de Bauru que participaram do Mestrado Interinstitucional pelo conhecimento transmitido e pela dedicação a este programa.

Aos queridos colegas de turma Célia, Cintia, Cynthia, Denilson, Jefferson, Maristela, Sérgio, Vânia pelo convívio de amigos que tivemos, que ficará para sempre.

Ao colega doutorando Lawrence pelo auxílio nos trabalhos de pesquisa e pela amizade.

À colega mestranda Natália, pela acolhida em sua casa e pelo total apoio para a conclusão deste trabalho.

A colega mestranda Leylha, pela dedicação na formatação deste trabalho.

Aos queridos funcionários, Ricardo secretário do Mestrado Interinstitucional e a todos do Departamento de Dentística com os quais construí uma bela amizade, porque sempre foram prestativos e eficientes em ajudar-me.

A todos os colegas do Mestrado Interinstitucional pela amizade e pela oportunidade de termos nos encontrado. Sentirei saudades. 
Agradeço ainda ...

Ao Prof. Doutor Adair Luiz Stefanello Busatto, pelo incentivo e porque sempre será para mim um exemplo de professor e pesquisador a ser seguido.

Ao Prof. Doutor Joao Carlos Gomes, pela constante motivação à pesquisa e pelas oportunidades de trabalho em conjunto.

Aos colegas de trabalho Ademir Céllio, Anita Segalla e Fábio Deitos porque torceram pelo meu êxito neste trabalho. 
Agradecimentos Institucionais

Ao Magnífico Reitor da UNIOESTE Wilson Luís Iscuissati, pela concessão de afastamento parcial das atividades para que fosse possível cursar este Mestrado.

A Sônia Lemanski, Diretora da Divisão de Capacitação Docente da Pró-Reitoria de Pesquisa e Pós-Graduação pela atenção e orientação a mim concedidas na tramitação do processo de afastamento parcial.

À Professora Ana Carla Marques da Silva, Diretora do Centro de Ciências Biológicas e da Saúde pelo incentivo para a qualificação docente.

Ao Coordenador do Curso de Odontologia da UNIOESTE Prof. Rolando Plumer Pezzini, pelo apoio e incentivo dado aos professores deste curso.

Aos professores do Colegiado de Odontologia da UNIOESTE porque foram realmente companheiros de trabalho, auxiliando nas atividades docentes quando não pude estar presente. Agradeço especialmente aos professores Júlio K. Ueda, Fernanda Lima, Rosana Santos e Carlos Nassar. O meu reconhecimento. 


\section{SUMÁRIO}

Lista de Abreviaturas e Símbolos ................................................................. $\mathrm{xi}$

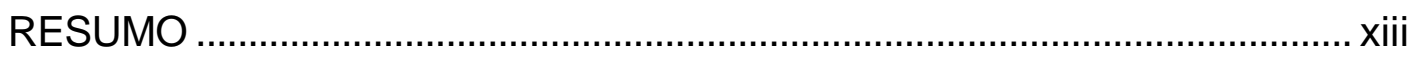

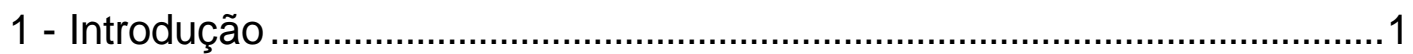

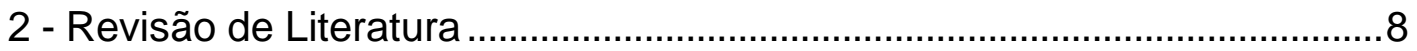

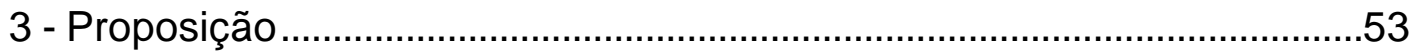

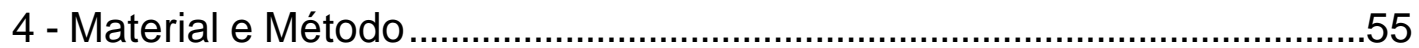

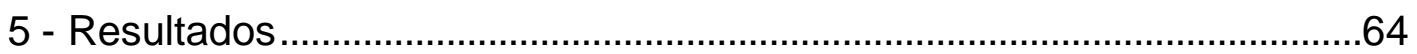

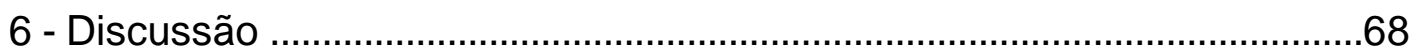

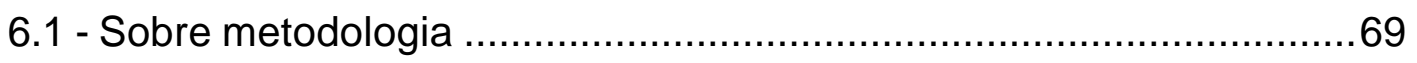

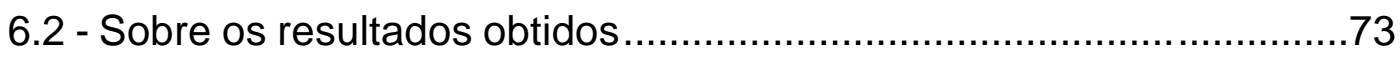

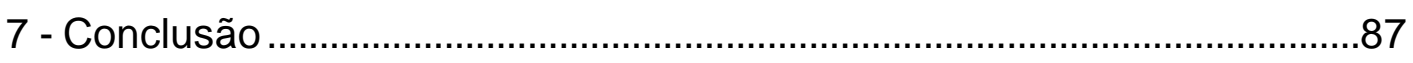

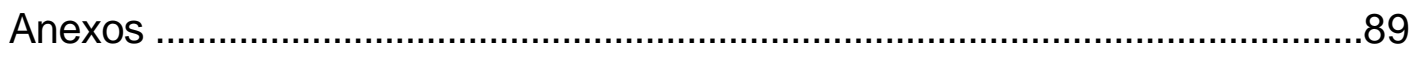

Referências Bibliográficas ...........................................................................96

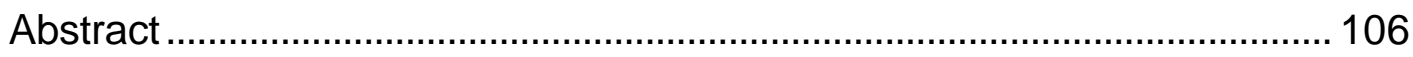




\title{
Lista de ABREVIATURAS e Símbolos
}

\author{
\%: $\quad$ Por cento \\ $\mu \mathrm{m}: \quad$ Micrometro \\ Bis-GA: Bisfenol glicidil acrilato \\ Bis-GMA: Bisfenol glicidil metacrilato \\ cm: $\quad$ Centímetro \\ CQ: $\quad$ Canforoquinona \\ DMAEMA: Dimetilnolaminoetil metacrilato \\ DMPTI: Dimetil-p-toluidina \\ EGDMA: Etilenoglicol dimetacrialto \\ FTIR: $\quad$ Fourier Transform Infrared Spectrometer \\ GC: $\quad$ Grau de conversão \\ GLM: $\quad$ Grau de liberdade média \\ In GaN: Índio nitrato de gálio \\ ISO: International Organization for Standardization \\ KHN: $\quad$ Número de dureza Knoop \\ LED: $\quad$ Light-emitting-diode \\ LH: $\quad$ Luz halógena \\ Min: $\quad$ Minuto \\ $\mathrm{mA}: \quad$ miliampere \\ $\mathrm{mm}$ : $\quad$ Milímetro \\ $\mathrm{mW} / \mathrm{cm}^{2}$ : Miliwatts por centímetro quadrado \\ NDV: $\quad$ Número de dureza Vickers \\ nm: $\quad$ Nanômetro \\ ${ }^{\circ} \mathrm{C}: \quad$ Graus Celsius (Graus Centígrados) \\ PAC: $\quad$ Fotopolimerizador de arco de plasma \\ PPD: $\quad$ Fenil-propanodiona \\ $\mathrm{RL}$ : $\quad$ Radicais livres \\ S: $\quad$ Segundo \\ TEGDMA: Trietilenoglicol dimetacrilato \\ UEDMA: Uretano dimetil dimetacrilato \\ W: Watt \\ $\mathrm{W} / \mathrm{cm}^{2}$ : Watts por centímetro quadrado
}




\section{RESUMO}

O objetivo deste estudo foi avaliar a resistência à tração de uma resina composta fotopolimerizada por diferentes fontes de luz e por diferentes tempos de ativação. Deste modo, foi utilizado um aparelho de luz halógena Curing Light 2500-3M $\left(670 \mathrm{~mW} / \mathrm{cm}^{2}\right)$ e outro do tipo LED Ultraled - Dabi-Atlante $\left(130 \mathrm{~mW} / \mathrm{cm}^{2}\right)$. Para confecção dos corpos de prova utilizoutse um conjunto de matrizes de aço inoxidável, composto de duas partes, sendo que cada parte apresentava um orifício central cônico com 8,0mm de diâmetro maior e 6,0mm de diâmetro menor e $1,0 \mathrm{~mm}$ de espessura. A resina composta utilizada foi a Z-250 (3M) nas cores A1 e A4. Foram confeccionados oito grupos de 10 espécimes, sendo quatro grupos fotopolimerizados com luz halógena e quatro com LED. Para luz halógena, dois grupos com resina Z-250 na cor A1, com tempos respectivos de 20s (G1) e 40s (G2) e dois grupos com cor A4, com tempos de 40s (G3) e 80s (G4). Da mesma forma para o LED; dois grupos com a resina Z-250 na cor A1, com tempos de 20s (G5) e 40s (G6) e dois grupos na cor A4, com tempos de 40s (G7) e 80s (G8) respectivamente. Dez minutos após a obtenção dos espécimes o conjunto foi adaptado a um dispositivo especial para permitir o acoplamento junto a uma máquina de ensaios universal e a realização do ensaio de tração, numa velocidade de movimento de $0,5 \mathrm{~mm} / \mathrm{min}$. Os valores obtidos foram submetidos à análise de variância ANOVA a dois critérios sendo estes, fonte de luz e tempo de polimerização. As médias e desvios padrão foram respectivamente: G1 - 14,13 \pm

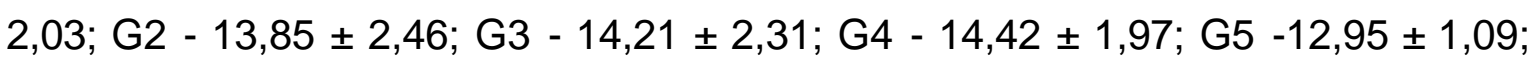
G6 - 13,46 $\pm 2,02$; G7 - 12,99 $\pm 1,29$; G8 $-14,25 \pm 2,8$. Concluiurse que: (1) $O$ aparelho fotopolimerizador LED foi tão efetivo na polimerização da resina composta quanto o aparelho de luz halógena. (2) O aumento do tempo de polimerização não exerceu influência na resistência à tração da resina composta, independente do tipo de aparelho fotopolimerizador e da cor do material. (3) A resistência à tração para a resina Z250 nas cores A1 e A4 não foi afetada pela variação do tempo de polimerização e pelas fontes de luz halógena e LED. 
1. INTRODUÇÃO 


\section{1 - INTRODUÇÃO}

As resinas compostas fotopolimerizáveis revolucionaram a prática da Odontologia Restauradora. Atualmente, estes sistemas dominam em grande parte o mercado de materiais restauradores estéticos diretos e, ao longo dos últimos dez anos, vêm sofrendo melhorias como: melhores propriedades mecânicas, grande variedade de cor, valor e saturação, permitindo a reprodução satisfatória das características ópticas do esmalte e da dentina ${ }^{6,9,20}$.

Previamente ao desenvolvimento das resinas fotopolimerizáveis, os compósitos eram auto ou quimicamente polimerizáveis, apresentando-se na forma de duas pastas. Uma pasta com o peróxido de benzoíla, gerador de radicais livres e a outra, uma amina terciária que, quando misturada ao peróxido dava início ao processo de polimerização dos grupos de metacrilato para formar uma matriz de cadeias poliméricas cruzadas. No entanto, desvantagens como a necessidade de mistura, falta de controle do tempo de polimerização, instabilidade de cor e porosidade da massa do material, acarretavam manchamento prematuro superficial e redução das propriedades físicas ${ }^{2,13,19,45,81}$.

$\mathrm{Na}$ década de 70, com o surgimento das resinas compostas polimerizáveis por luz, grandes melhorias foram conseguidas, tais como: o maior tempo de trabalho; a possibilidade de acomodação do material à cavidade e só depois dar início à polimerização, devido a sua apresentação em pasta única; além de significativas melhoras nas propriedades físicas. A primeira resina polimerizável 
por luz lançada no mercado tinha sua polimerização iniciada por uma radiação ultravioleta, a qual emitia energia luminosa intensa, na faixa de ondas que oscilava entre 320 e 365 nanômetros. Foi uma revolução no mercado de materiais restauradores. Entretanto, desvantagens como os malefícios da radiação ultravioleta e a limitada profundidade de polimerização foram razões suficientes da sua total substituição pelos sistemas ativados pelo espectro azul de luz visível $^{2,18,26,45}$

Nas resinas compostas fotopolimerizáveis por luz visível, o processo de polimerização inicia-se com a absorção de luz pela molécula do fotoiniciador. Este fotoiniciador na maioria das vezes é uma $\alpha$-diketona, a canforoquinona (CQ). Ao absorver energia luminosa com determinados comprimentos de onda (em $\mathrm{nm}$ ) a $\mathrm{CQ}$ passa para um estado excitado, denominado estado tripleto ${ }^{48,56,63,80}$. A combinação da $\mathrm{CQ}$ com uma molécula intermediária, a amina terciária, leva à formação de radicais livres $(R L)$ dando início ao processo de polimerização. Daí em diante o processo continua de maneira semelhante aos sistemas de duas pastas. A luz que interage com o fotoiniciador funciona como fonte de energia necessária para promover a excitação da molécula, bem como para a formação de ligações químicas entre monômeros resinosos durante o processo de cura. A energia total fornecida para que determinada resina composta polimerize é o produto da intensidade de luz emitida pelo aparelho fotopolimerizador (em $\mathrm{mW} / \mathrm{cm}^{2}$ ) pelo tempo de exposição à luz (em segundos) $)^{48,57,79,80}$. Então, os principais fatores responsáveis pelo sucesso das restaurações estéticas realizadas em resina composta são: emissão suficiente de intensidade de luz, 
correto comprimento de onda emitido e tempo de exposição adequado $38,63,80$. Portanto, a energia luminosa emitida pela fonte deve pertencer à faixa do espectro de luz (em nm) capaz de sensibilizar o fotoiniciador da resina composta $^{48}$. Desta forma, a qualidade e o bom funcionamento do aparelho fotopolimerizador são diretamente responsáveis pelo polímero formado $0^{2,3,6,56,57}$.

A polimerização insuficiente da resina composta está entre as principais causas de insucesso clínico, caracterizado pelo comprometimento estético com maior tendência ao manchamento superficial, possibilidade de infiltração marginal, devido à incapacidade de polimerização das camadas mais profundas e teor aumentado de monômeros residuais ${ }^{19,64,66}$. Segundo NAGEM FILHO ${ }^{45}$ uma deficiente polimerização está associada à redução das propriedades físicoquímicas da resina composta, podendo resultar em menor dureza superficial, resistência reduzida à compressão e aumento da possibilidade de deslocamento da restauração devido à menor retenção ${ }^{2,13,4}$. Portanto, o sucesso clínico de uma restauração está diretamente relacionado à qualidade do polímero formado pelo processo de polimerização.

A fonte de luz azul visível mais popular aos profissionais da área odontológica é a convencional luz halógena de quartzo-tungstênio (LH), porém esta apresenta algumas desvantagens que limitam sua vida útili,41,67,80. Em conseqüência da alta temperatura em que as lâmpadas operam, ocorrem danos no bulbo, no refletor e no filtro, alterando a qualidade da luz emitida, afetando o grau de polimerização do material, sem que o profissional possa se aperceber ${ }^{3,42}$. Além disso, tem-se demonstrado que muitos aparelhos que emitem LH não 
alcançam a mínima intensidade de luz especificada pelos fabricantes, devido à falta de manutenção e a não checagem da intensidade de luz do mesmo, ou ainda pelo fato do filtro e/ou lâmpada não serem substituídos regularmente ${ }^{3}$. Nos aparelhos de LH o filtro tem a importante função de selecionar a energia luminosa no comprimento de onda necessário para sensibilizar o fotoiniciador, já que uma grande quantidade de energia gerada não é efetiva na polimerização, gerando apenas calor ${ }^{3,48,63}$.

Novos modelos alternativos de aparelhos surgiram no mercado. A exemplo disto, as lâmpadas de arco de plasma e o laser de argônio são os de maior custo, face à tecnologia envolvida ${ }^{39,52,73,75}$. Não obstante os fabricantes destaquem a significativa redução no tempo de polimerização, observa-se em publicações recentes que as propriedades mecânicas do material são comparáveis àquelas conseguidas com lâmpadas convencionais ${ }^{52,75}$. Estudos científicos têm demonstrado que pequenos tempos de fotopolimerização proporcionam impacto negativo nas propriedades mecânicas do material ${ }^{52,73,68}$ e que a qualidade de adaptação marginal de restaurações realizadas com resina composta pode ser melhorada por meio do emprego de baixas intensidades de luz ${ }^{1,68}$.

Uma nova e promissora tecnologia que surgiu no mercado como opção para polimerizar materiais fotossensíveis sem os inconvenientes dos aparelhos de luz halógena é o LED (light-emitting-diode) que são fontes de luz no estado sólido, compostos pela combinação de diferentes semicondutores para emissão de luz azul. Trata-se de uma tecnologia marcadamente diferente de uma lâmpada halógena, com a grande vantagem de que a energia luminosa produzida, a partir 
do nitrato de gálio, concentra-se em uma estreita faixa do espectro de luz visível, a qual coincide com espectro de absorção máxima da $C Q(468 n m)^{5,18,24,25,29}$. Os aparelhos tipo LED não possuem filtros, uma vez que comprimentos de onda desnecessários não são gerados e, portanto, há mínima geração de calor. Ainda dentro das vantagens deste aparelho, este possui uma longa vida útil, de $10 \mathrm{mil}^{41}$ a 100 mil horas $^{24}$, sem significante degradação do fluxo de luz com o passar do tempo além de serem altamente resistentes aos atos de ligar e desligar durante o seu uso rotineiro ${ }^{17,24,39,40}$. A literatura atual tem mostrado a efetividade dos aparelhos LED na polimerização das resinas compostas em testes de profundidade de polimerização, resistência à compressão e resistência flexural ${ }^{24,39,64}$. Não obstante as características favoráveis, já demonstradas, destes aparelhos, verifica-se que a maioria dos artigos publicados sobre a qualidade do compósito formado refere-se apenas à profundidade de fotopolimerização e à resistência à compressão destes materiais. Alguns autores como STAHL et al. ${ }^{67}$, DUNN; VUSH ${ }^{14}$ já apontaram a necessidade de informações adicionais sobre as propriedades mecânicas dos compósitos polimerizados com LED, a fim de poder julgar o seu potencial com maior propriedade. Nenhuma característica deve ser utilizada isoladamente na análise da real qualidade do material $^{26}$. A avaliação da resistência à tração constitui-se em fator primordial para correlacionar a qualidade do polímero com o comportamento intrínseco inerente ao mesmo ${ }^{43}$. Isto se aplica principalmente aos materiais restauradores usados onde a incidência de maior esforço mastigatório e estresse podem exacerbar defeitos inerentes ao material, resultando em inadequada resistência à fratura do mesmo $^{4,14,30,67}$. 
Embora os aparelhos LED emitam energia luminosa em comprimento de onda compatível com o fotoiniciador mais usado nas resinas, a $\mathrm{CQ}$, dúvidas têm sido levantadas por parte da comunidade odontológica, visto que a intensidade de luz usualmente emitida pelo LED é inferior a dos aparelhos de luz halógena. Face ao exposto, a presente pesquisa objetiva avaliar a resistência à tração ou coesiva de uma resina composta com duas cores distintas, em função da fonte de polimerização (luz halógena ou LED) e dos tempos de ativação, consubstanciando a aplicabilidade clínica do LED como uma tecnologia efetiva na polimerização de materiais fotossensíveis. 
2. REVISÃo dE LITERATURA 


\section{2 - REVISÃo de LITERATURA}

ASMUSSEN², em 1982, observou a influência da composição química da resina composta na polimerização, relacionando-a com as propriedades físicas do compósito. O grau de conversão determina as propriedades mecânicas do compósito formado e reflete a eficácia da polimerização. O mesmo pode variar em função da estrutura dos monômeros envolvidos e da capacidade dos metacrilatos de se difundirem através da matriz polimérica e reagir com radicais terminais das cadeias. A dureza e a resistência à tração da resina composta estavam relacionadas com a quantidade de ligações duplas remanescentes, com o grau de conversão e também com a natureza dos monômeros e sistemas catalisadores envolvidos. Uma menor quantidade de inibidor pode ter causado uma maior proporção de ligações duplas convertidas para serem ligadas a outras ligações cruzadas de polímeros. No entanto, ligações convertidas não necessariamente indicam maior grau de conversão visto que a reação pode ter ocorrido com oxigênio ou com uma molécula do inibidor sem aumentar as ligações cruzadas.

YEARN; MACCLESFIELD ${ }^{80}$, em 1985, publicaram uma revisão sobre os principais fatores que determinam as características de cura e, conseqüentemente da performance das resinas fotopolimerizáveis. Percebeu-se que, dentre os fatores que afetam a polimerização, a composição química das resinas é importante na determinação da proporção em que se procederá a polimerização. Estas diferenças na composição química podem ser com relação ao monômero envolvido (Bis-GMA ou dimetacrilato de uretano,) ou a diferentes 
combinações de catalisadores diketona/amina. Materiais com a mesma composição (resinosa e de partículas), porém com diferentes combinações de catalisadores, variaram na profundidade de polimerização (para catalisador A, $1 \mathrm{~mm}$ de profundidade de cura e para $\mathrm{B}, 2-3 \mathrm{~mm})$. As principais variáveis na composição que determinam o grau de polimerização, em qualquer camada do compósito, são aquelas que influenciam a habilidade da luz de atingir a respectiva camada. São fatores que facilitam ou impedem a transmissão da luz. Enquanto alguma luz é absorvida pelo próprio catalisador os principais fatores inibidores são as propriedades ópticas da mistura resina/partículas. Mesmo usando-se a mesma combinação resina/partículas, a diferença na transmissão pode ocorrer se os tamanhos das partículas forem diferentes, porque isto pode influenciar a dispersão da luz. Para qualquer formulação de resina, as características de cura são governadas pela quantidade e qualidade da luz proveniente da fonte de radiação empregada, sendo esta igualmente dependente do operador, o qual controla o tempo de ativação e a distância da ponta ativa. Ao relacionar o comprimento de onda da luz incidida ao perfil de dureza, a faixa de $476,5 \mathrm{~nm}$ foi mais efetiva. Na extensão além de 500nm o benefício é mínimo e há produção de calor, o que pode adversamente afetar a polpa e os tecidos moles. Do mesmo modo, comprimentos de onda na região ultravioleta, abaixo de 400nm, também contribuem pouco e devem preferivelmente ser eliminados.

FERRACANE et al. ${ }^{18}$, em 1986, determinaram a profundidade de polimerização de resinas compostas fotopolimerizáveis por luz visível através de teste de dureza Knoop e de análise de espectroscopia infravermelha. Resinas 
compostas (Prisma Fine, Prisma Fil e Aurafill) de diferentes composições e cores foram utilizadas na confecção de corpos de prova com $5 \mathrm{~mm}$ de espessura, os quais foram expostos à luz durante 40 segundos, à distância de $2 \mathrm{~mm}$ da superfície do material. Após o armazenamento durante 24 horas, à temperatura de $37^{\circ} \mathrm{C}$, os espécimes foram submetidos ao teste de dureza Knoop com impressões realizadas a cada milímetro do material polimerizado, até a profundidade máxima de $4 \mathrm{~mm}$. O grau de conversão foi avaliado por meio da análise de espectroscopia, em corpos de prova confeccionados com matrizes metálicas de $4 \mathrm{~mm}$ de diâmetro e $3 \mathrm{~mm}$ de espessura. A partir dos resultados obtidos, os autores concluíram que as resinas compostas de cores claras (L) apresentaram maior profundidade de polimerização do que as de cores escuras (Y, G, GB). Entretanto, a cor mais escura da resina composta Aurafill (GB) apresentou resultado equivalente ao obtido com a cor mais clara (L) do mesmo material. Os autores relataram ainda que a profundidade de polimerização pode ser menos dependente da cor da resina composta do que de outros fatores, como por exemplo, a capacidade de transmissão da luz através do volume do material.

FAN et al. ${ }^{15}$, em 1987, mediram a irradiação, no comprimento de onda de 450 a 500nm, de nove unidades de polimerização de luz visível e relacionaram os valores de dureza Knoop das resinas compostas Prisma Fine e Silux, com diferentes valores de voltagem. Com o objetivo de determinar uma possível relação entre as variações de voltagem, intensidade de luz e profundidade de cura, os autores confeccionaram corpos de prova de $2 \mathrm{~mm}$ de espessura e determinaram os valores de dureza nas superfícies de topo e de base dos 
materiais analisados. Dentre as conclusões, observourse que a variação de voltagem afetou a intensidade de luz emitida pelos fotopolimerizadores, onde os maiores valores de dureza foram proporcionados pela unidade de luz regulada em $130 \mathrm{~V}$, associada à intensidade de luz máxima de $246,3 \mathrm{~mW} / \mathrm{cm}^{2}$. Entretanto, não foi possível estabelecer um valor ideal de intensidade de luz capaz de promover a polimerização efetiva das resinas compostas avaliadas.

TAIRA et al. ${ }^{71}$, em 1988, propuseram-se a identificar se num grupo de resinas compostas, todas tinham a $\mathrm{CQ}$ como fotoiniciador; assim como medir a concentração da mesma e identificar o agente redutor. Observourse que variações ligadas a estes componentes podem explicar diferentes valores de polimerização entre as resinas estudadas. Foi utilizada cromatografia de gás líquido para determinação dos componentes diluentes extraídos da resina composta. Espectroscopia de Mass foi usada para confirmação dos dados obtidos. Os resultados mostraram que todas as resinas examinadas incluíam a $\mathrm{CQ}$ como fotossensibilizador. A concentração da $\mathrm{CQ}$ na fase resinosa, entretanto, variava de $0,17 \%$ para $1,03 \%$ em peso. A resina composta híbrida tendia a ter maior concentração de $\mathrm{CQ}$ do que a de micropartícula, provavelmente devido à cor amarela da CQ, o que limita sua quantidade por motivos estéticos. Quanto ao agente redutor, duas de sete marcas continham dimetilaminoetil metacrilato (DMAEMA), e uma delas, dimetilp-toluidina (DMPTI). A proporção da mistura destes com a $\mathrm{CQ}$ nas três resinas analisadas também variou. A concentração do agente redutor pode aumentar a liberação dos radicais livres por ser responsável 
pela doação de elétrons para a $\mathrm{CQ}$, fazendo com que a polimerização ocorra de forma mais rápida e intensa.

McCABE; CARRICK ${ }^{38}$, em 1989, desenvolveram um método de monitorar a intensidade da radiação de oito unidades fotopolimerizadoras por meio do uso de uma fotocélula condutiva de sulfato de cádmio, cuja resistência elétrica varia conforme a quantidade de luz que incide sobre a mesma. Filtros de seleção de comprimento de onda de banda extensa permitiram medir a intensidade de luz e filtros de banda estreita permitiram medir a intensidade em 460 a 480nm. A profundidade de polimerização de quatro resinas compostas foi avaliada nas diferentes condições de luz. As unidades de luz, com maior intensidade a 470nm, geralmente produziram maior profundidade de cura, sendo que esta era inversamente proporcional à atenuação da luz nesta faixa de emissão. Os resultados indicaram que ambos intensidade de luz da fonte e poder de atenuação do material influenciaram na profundidade de cura.

HANSEN; ASMUSSEN²6, em 1993, estudaram a relação existente entre a dureza superficial da resina composta de micropartícula (Silux Plus) e a profundidade de polimerização obtida com dez aparelhos fotopolimerizadores de diferentes marcas comerciais. O teste de dureza Vickers foi realizado nas superfícies de base e de topo de corpos de prova confeccionados em matrizes de teflon com 3,6mm de diâmetro. Após 7 dias de armazenamento à temperatura de $36,5 \pm 0,5^{\circ} \mathrm{C}$, os corpos de prova foram analisados por meio de cinco impressões realizadas em cada superfície. A profundidade de polimerização foi determinada por meio do teste de raspagem da resina composta fotopolimerizada com dez 
aparelhos de luz. Cavidades cilíndricas foram confeccionadas em dentes molares humanos extraídos com 4,5mm de diâmetro e 8 a $10 \mathrm{~mm}$ de espessura. Após análise dos resultados, os autores relataram a inexistência de correlação entre a dureza superficial e a profundidade de polimerização, pois o aparelho fotopolimerizador que apresentou mínima profundidade de polimerização, foi capaz de proporcionar valores de dureza superficial semelhantes àqueles obtidos com o aparelho que promoveu maior profundidade de polimerização. Segundo os autores, a superfície externa da resina composta polimerizada omite, em alguns casos, porções de resina composta mal polimerizadas ou até mesmo não polimerizadas. Por este motivo, não se deve afirmar a qualidade de um fotopolimerizador baseando-se apenas nos resultados de dureza da superfície externa da resina composta.

FOWLER; SWARTZ; MOORE ${ }^{20}$, em 1994, avaliaram o efeito da redução da intensidade de luz sobre a profundidade de polimerização em várias resinas compostas (APH, Occlusin, Prisma-Fil e Silux Plus) e também a capacidade de profissionais compararem a qualidade de polimerização de resinas polimerizadas por diferentes intensidades de luz. Filtros de densidade neutra foram acoplados ao aparelho fotopolimerizador Coe Lite com o objetivo de bloquear a emissão da luz em 10, 20, 30,40,50,60, e 70\% da irradiação máxima proporcionada pelo aparelho. Os radiômetros Macam (Macam Photometrics Ltd.) e Curing Raiometer (Demetron Res. Corp.) foram utilizados para registrar os valores de intensidade de luz. Corpos de prova com $3 \mathrm{~mm}$ de espessura foram confeccionados com cada uma das resinas compostas e fotopolimerizadas durante 30 e 60 segundos com 
cada valor de intensidade de luz $\left(400,300,200,175,150,125,100\right.$ e $\left.50 \mathrm{~mW} / \mathrm{cm}^{2}\right)$. A profundidade de polimerização foi determinada, por meio do teste de dureza Barcol, nas superfícies de topo e de base dos corpos de prova, imediatamente e 1 hora após a sua confecção. Os resultados indicaram que a polimerização da superfície de topo das resinas compostas testadas foi pouco afetada pela variação da intensidade de luz e pelo tempo de exposição, porém ambos os fatores influenciaram a dureza na profundidade de $3 \mathrm{~mm}$. O tempo de 60 segundos de exposição à luz promoveu maior dureza superficial, mesmo com intensidade de luz reduzida. Quanto à avaliação da qualidade de polimerização da resina composta pelos profissionais, comparando-se as superfícies de discos de dureza e o material avaliado, os resultados foram negativos. Os autores recomendaram a utilização de radiômetros para o monitoramento dos fotopolimerizadores, pois os discos de dureza pré-fabricados não mostraram resultados confiáveis.

BARGHI; BERRY; HATTON ${ }^{3}$, em 1994, pesquisaram os fatores que deveriam ser mais bem controlados pelo clínico no sentido de assegurar a qualidade das restaurações polimerizadas com aparelhos de luz halógena. Visto que, apesar da comprovada eficiência, estes aparelhos dependem de constantes cuidados, ao passo que se observam muitas irregularidades na rotina dos consultórios quanto a estes fatores. Os dentistas em consultórios particulares utilizam aparelhos fotopolimerizadores inadequados e muitos desconhecem que a intensidade apresentada por seus aparelhos é insuficiente para polimerizar completamente a resina composta. Os autores avaliaram 209 aparelhos em uso 
nos consultórios odontológicos. As leituras foram relacionadas ao tipo do aparelho, ao fabricante, à freqüência de uso, à condição da unidade, à idade, à freqüência de troca do bulbo, à potência em watts do bulbo e à satisfação do profissional com o aparelho. Concluiurse que 30\% dos aparelhos possuíam uma saída de intensidade menor que $200 \mathrm{~mW} / \mathrm{cm}^{2}$, valor inadequado para propiciar polimerização suficiente. Para os aparelhos de luz halógena, a intensidade de luz é inversamente proporcional à idade da unidade, 10\% possuíam filtros rachados ou com bolhas e muitos dos dentistas nunca haviam trocado a lâmpada de seus aparelhos. O grau de polimerização é, em grande parte, responsável pela qualidade estética o comportamento clínico do material. Variáveis como cor, tipo de compósito, fonte de luz e distâncias devem ser consideradas quando se examina a intensidade de energia de uma unidade fotopolimerizadora e o grau de conversão de monômeros.

RUEGGEBERG; CAUGHMAN; CURTIS ${ }^{57}$, em 1994, verificaram o dramático efeito da duração da exposição e intensidade da fonte sobre a profundidade de polimerização. Por meio da simulação de uma restauração em forma de cilindro obtiveram-se fatias de compósito que podiam ser removidas do topo ou de uma distância de 1, 2 e $3 \mathrm{~mm}$ internamente à superfície. Os espécimes, feitos com resina composta de micropartícula e híbrida de cores universal e cinza, foram polimerizados usando-se várias intensidades e diferentes tempos de exposição para cada nível dentro do cilindro. A polimerização resultante de cada tratamento foi determinada usando espectroscopia de infravermelho. Para reduzir a intensidade da luz, utilizaram-se filtros que a 
reduziam de $100 \%\left(800 \mathrm{mWcm}^{2}\right)$ a $29,2 \%\left(233 \mathrm{mWcm}^{2}\right)$. Os resultados da análise de variância a dois critérios indicaram que, na superfície da resina, somente o tempo de exposição é um fator significante, contribuindo para a conversão de monômeros. Quando se polimeriza $1 \mathrm{~mm}$ do compósito, ambos tempo de exposição e intensidade tornam-se fatores significantes. Nos níveis de 2 a $3 \mathrm{~mm}$ de espessura, os fatores: tempo de exposição, intensidade e suas interações contribuem para a polimerização da resina. Na superfície, os tempos de 40 ou 60 segundos produziram espécimes similarmente polimerizados. Exposições de 60 e 80 segundos também foram similares em resultados. A $1 \mathrm{~mm}$ de profundidade, todos os tempos de exposição produziram polimerizações significantemente diferentes, com exceção de 60 e 80 segundos. Isto também foi percebido para 2 e $3 \mathrm{~mm}$, em que há diferenças estatísticas nos valores de conversão entre todas as combinações de tempos. Em profundidades maiores que $2 \mathrm{~mm}$, pobres valores de cura foram encontrados e a polimerização foi muito susceptível a mudanças de intensidade de luz e tempo de exposição. Por estes resultados, recomendam-se tempos de exposição de rotina de 60 s, com intensidades de luz de pelo menos $400 \mathrm{~mW} / \mathrm{cm}^{2}$ (medido por um radiômetro comercial). Espessuras de camadas incrementais não deverão exceder $2 \mathrm{~mm}$, sendo a espessura de $1 \mathrm{~mm}$ a ideal e unidades com intensidade inferior a $233 \mathrm{~mW} / \mathrm{cm}^{2}$ não deverão ser usadas, devido a suas pobres características de cura. O autor também percebeu que, em $2 \mathrm{~mm}$ de profundidade, o aumento do tempo de exposição para 80s não proporcionou aumentos significativos de polimerização em relação a 60s. 
MILLS ${ }^{40}$, em 1995, cita o LED como uma alternativa de fonte polimerizadora, a qual utiliza uma baixa voltagem e possui um longo tempo de vida útil, podendo ser bem compactos e emitir luz num específico comprimento de onda. O dispositivo teria maior resistência a choques e vibrações do que as lâmpadas incandescentes. O LED verde e amarelo já estavam disponíveis há muitos anos e produziam luz pela passagem de eletricidade por uma junção de arsenato de gálio. Os LEDs azuis, disponíveis há aproximadamente oito anos, são de baixa intensidade de luz. O LED azul superbrilhante foi primeiramente usado em marcadores coloridos de alta velocidade e na transmissão de dados por líquidos, por meio de uma junção de nitrato de gálio. O autor testou então uma unidade com ponta de $5 \mathrm{~mm}$ de diâmetro, com comprimento de onda de $450 \mathrm{~nm}$, 1000 milicandelas, 1,2mW. Uma amostra de resina composta de $5 \mathrm{~mm}$ de diâmetro por $2 \mathrm{~mm}$ de espessura, foi polimerizada por $80 \mathrm{~s}$, com $2 \mathrm{~mm}$ de distância da fonte de luz. Estes resultados eram animadores, já que o comprimento de onda emitido era $20 \mathrm{~nm}$ inferior ao pico recomendado para materiais fotossensíveis e o dispositivo funcionou com $50 \%$ de energia somente. O autor concluiu a publicação sugerindo que o LED poderia ser montado de forma compacta tipo tocha, possivelmente focado com lente, melhorando estes primeiros achados, vislumbrando um futuro próximo onde o dentista seria visto usando o LED não somente como ponteira em palestras mas também no consultório.

NAKAMURA; SENOH; IWASA ${ }^{46}$, em 1995, pesquisadores pertencentes ao Departamento de Desenvolvimento e Pesquisa da indústria japonesa Nichia 
Chemical Industries, por meio da colocação de uma fina camada de InGaN modificando a estrutura do LED azul produziram $4,8 \mathrm{~mW}$ a $20 \mathrm{~mA}$ com pico de emissão de comprimento de onda a 450nm, correspondendo à eficiência de 8,7\%. Estes foram os primeiros LEDs azuis de alto brilho. Estes valores de potência final e de eficiência quântica foram os maiores até então reportados para LEDs azuis. Era o início da geração dos LEDs com alta potência de luz azul em um estreito espectro de emissão.

CAUGHMAN; RUEGGEBERG; CURTIS $^{6}$, em 1995, publicaram uma revisão de literatura para o clínico, que tratava dos efeitos das técnicas restauradoras relacionadas à fotopolimerização em odontologia. Os autores afirmaram que o processo depende da intensidade de irradiação e sua duração, vendo como fatores que podem ser controlados pelo clínico, já que com a evolução dos aparelhos de luz halógena, pode-se adquirir equipamentos com boa intensidade de luz e com possibilidades de correto controle do tempo de exposição. Os fatores que afetam a intensidade de irradiação dentro do compósito são a espessura do material, sua composição e cor. Destes, a espessura do material é o mais importante, podendo ser controlado pelo clínico e é um fator chave na determinação do sucesso de uma restauração fotopolimerizável. Os autores recomendam incrementos não maiores que $2 \mathrm{~mm}$. Partículas de 0,01 a 1micrometro dispersam a luz porque estes tamanhos são semelhantes ao comprimento de onda emitida pelo fotopolimerizador. Para cores escuras, que atenuam a emissão de luz, absorvendo-a à medida que passa pelo corpo da restauração, é prudente diminuir o incremento para $1 \mathrm{~mm}$. O esquema de 
manutenção dos aparelhos deve ser seguido, particularmente aos sinais de degradação do bulbo, refletor e ponta óptica do aparelho. Indica-se o uso periódico de um radiômetro. Para os autores, a duração da exposição é fator limitante quando a intensidade de luz for maior que 280 a $300 \mathrm{~mW} / \mathrm{cm}^{2}$, quando o incremento for de $2 \mathrm{~mm}$ ou menos e a ponta polimerizadora estiver a menos de $6 \mathrm{~mm}$ da superfície. Materiais polimerizados adequadamente terão uma influência positiva nas propriedades físicas e biológicas da restauração e deverão colaborar para o sucesso clínico.

MIYAZAKI et al. ${ }^{43}$, em 1996, investigaram as características da resina fotopolimerizada por meio da análise de propriedades mecânicas. Espécimes confeccionados em matrizes individuais ranhuradas de $25 \mathrm{~mm} \times 2,5 \mathrm{~mm} \times 5 \mathrm{~mm}$ com 5mm de entalhe, foram preparados para medições de tenacidade à fratura. Para o teste de resistência flexural utilizourse uma matriz de aço inoxidável de $25 \mathrm{~mm} \times 2 \mathrm{~mm} \times 2 \mathrm{~mm}$. A resina foi condensada dentro da matriz e o terço médio do espécime foi primeiro ativado por $30 \mathrm{~s}$ com $400 \mathrm{~mW} / \mathrm{cm}^{2}$, por 60 s com $200 \mathrm{~mW} / \mathrm{cm}^{2}$ ou por 120 s com $100 \mathrm{~mW} / \mathrm{cm}^{2}$. Os demais terços foram ativados pela mesma intensidade e empo. Após $24 \mathrm{~h}$ à $37^{\circ} \mathrm{C}$ em água, três pontos de teste foram feitos com uma distância de extensão de $20 \mathrm{~mm}$, com velocidade média de 0,5mm/min. Por meio do teste ANOVA seguido de Newman-Keuls compararamse os dados obtidos de cada grupo. Entre as três condições de cura para cada material, não houve diferenças significantes na tenacidade à fratura, resistência flexural e módulo flexural. Os valores foram similares quando a mesma quantidade de energia de polimerização foi usada (intensidade de luz pelo tempo 
de ativação). Propriedades mecânicas incluindo, tenacidade à fratura, resistência flexural e módulo de elasticidade são importantes propriedades de materiais restauradores usados onde a mastigação severa pode propagar defeitos inerentes ao material. Avaliando-se propriedades mecânicas, é possível relacionar o efeito da intensidade de luz e tempo de exposição sobre as mesmas.

SHORTALL; HARRINGTON ${ }^{65}$, em 1996, publicam um guia para seleção, uso e manutenção de aparelhos fotopolimerizadores e afirmam que intensidade de luz e um correto espectro de distribuição estão relacionados com boa profundidade de cura e grau de conversão das resinas. A uma espessura de 1 $2 \mathrm{~mm}$ de resina sobreposta, ocorre a redução na intensidade de luz e taxa de polimerização. No entanto, somente um pequeno aumento na profundidade de polimerização pode ser esperado se a intensidade de luz ou tempo de exposição forem duplicados. O tempo de ativação de 40 s para espessura de $2 \mathrm{~mm}$ parece ser apropriado. Para os aparelhos de luz halógena, a potência da lâmpada varia de 35 a 150W, o que não indica eficiência da mesma. A extensão do espectro de emissão de luz vai de 300 a 1000nm incluindo energia do infravermelho e ultravioleta, razão pela qual os fabricantes colocam um filtro entre a lâmpada e o guia de luz para limitar a energia radiante a uma extensão do espectro efetiva para polimerização de materiais fotossensíveis e eliminação do calor produzido. A radiação adequada está na faixa de 400 a 500nm.

HARRINGTON; WILSON; SHORTALL ${ }^{27}$, em 1996, desenvolveram um método para determinar o tempo de irradiação apropriado para aparelhos fotopolimerizadores na cura de diferentes resinas compostas e para monitorar a 
energia de irradiação transmitida pela resina. Usourse um radiômetro computadorizado e, através de teste de microdureza para a superfície de topo da resina foi possível verificar a validade do método pela performance da fonte de luz em tempo de ativação estipulado comparando-se com 60 s de ativação. Os autores obtiveram, em condições ideais, tempos mínimos de 16 a 44s para polimerizar $2 \mathrm{~mm}$ de espessura para as diferentes combinações de materiais/cor/unidades polimerizadoras. Da mesma forma, observourse que a duração da irradiação para resinas de diferentes cores, porém do mesmo produto, são similares, provavelmente por terem a mesma composição química e que, frente às médias obtidas, o tempo de 20s preconizado por alguns fabricantes para $2 \mathrm{~mm}$ de espessura pode ser insuficiente para obtenção de um compósito adequadamente polimerizado.

Ainda em 1996, SHORTALL; HARRIHGTON ${ }^{63}$, avaliaram a microdureza da superfície da base de espécimes de três tipos de resina composta com $2 \mathrm{~mm}$ de espessura quando curadas com doze aparelhos fotopolimerizadores. Relacionour se a mudança na dureza de superfície da base com medidas de intensidade de luz por meio de um radiômetro. Os autores demonstram a diferença ao se usar o radiômetro com janela de abertura larga, do qual se obtém a média da potência de toda a ponta ativa do aparelho, em comparação aos valores com a janela de abertura pequena $(4 \mathrm{~mm})$, que estabelece a medida do pico de densidade de energia do aparelho. Apesar dos fabricantes de radiômetros sugerirem relação direta de intensidade com profundidade de cura, deve-se considerar esta característica ao se avaliar a leitura da intensidade obtida. As médias de 
intensidades variaram de $34 \mathrm{~mW} / \mathrm{cm}^{2}$ a $725 \mathrm{~mW} / \mathrm{cm}^{2}$. A composição do material influenciou no grau de polimerização por 40 s para espessura de $2 \mathrm{~mm}$, sendo que nestas condições, menos da metade dos aparelhos polimerizaram adequadamente a resina de micropartícula. Apenas um dos aparelhos testados não polimerizou satisfatoriamente a resina composta híbrida com 40 s de exposição. Um nível de polimerização reduzida para a superfície da base ocorreu com intensidade de luz menor que $300 \mathrm{~mW} / \mathrm{cm}^{2}$. Encontrou-se uma significante correlação entre dureza de superfície de base e intensidade de luz. Padronizando-se a área de recepção de luz do radiômetro a um diâmetro similar ao do espécime a ser polimerizado melhorourse a correlação entre intensidade de luz e dureza de superfície de base.

ARAÚJO; ARAÚJO; FERNANDES ${ }^{1}$, em 1997, mediram a intensidade de luz e o calor irradiado de aparelhos fotopolimerizadores de luz halógena e a possível relação com o tempo de uso destes aparelhos. Foram avaliados 105 aparelhos de 16 modelos diferentes. Destes, 60 com menos de cinco anos foram considerados novos e 45, antigos. Encontrourse uma relação favorável entre alta intensidade de luz e baixa irradiação de calor para aparelhos novos. Para os aparelhos novos $75 \%$ apresentavam-se adequados para o uso e entre os antigos apenas $11,1 \%$.

NOMOTO $^{48}$, em 1997, avaliou a influência do comprimento de onda na polimerização das resinas compostas fotopolimerizáveis e definiu o mais adequado para a polimerização com uma resina experimental e um aparelho de luz visível. Mediu-se a intensidade de luz por meio de um radiômetro (Ll-190S, Li- 
Cor Inc.); utilizando-se, para a seleção do comprimento de onda, um filtro de banda estreita e um filtro de densidade neutra. O pico máximo de absorção para a $\mathrm{CQ}$ foi de $467 \mathrm{~nm}$, sendo que o grau máximo de conversão ocorreu a 470nm. $\mathrm{Na}$ faixa de extensão de 450-490nm o grau de conversão é fracamente sensível ao comprimento de onda. A intensidade de luz dentro desta extensão é mais importante do que o pico de comprimento de onda. Fora desta extensão, entretanto, a dependência do comprimento de onda é muito mais forte e a taxa de conversão diminui rapidamente. Conseqüentemente, a intensidade e comprimento de onda ótimos para polimerização por um aparelho fotopolimerizador ideal deveria localizar-se dentro da extensão 450-490nm, para os compósitos que possuem a CQ como fotoiniciador. Com 5 s de exposição, ambos grau de conversão e conversão de polimerização foram afetados pelo comprimento de onda, porque a absorbância da $\mathrm{CQ}$ afeta fortemente a polimerização, especialmente no estágio inicial. O autor enfatiza que a intensidade de luz no comprimento de onda de $470 \mathrm{~nm}$ pode ser um guia para eficiência em polimerização. Somente aqueles comprimentos de onda fortemente absorvíveis pelo fotoiniciador são úteis na fotopolimerização.

VARGAS; COBB; SCHMIT ${ }^{75}$, em 1998, compararam a polimerização da resina composta, de acordo com a microdureza, com o aumento da profundidade usando um laser de argônio (LA) e uma LH. Foram confeccionados cinco espécimes por grupo por meio da injeção de resina composta (de micropartícula Silux Plus e híbrida - TPH) dentro de um molde de teflon retangular de $3 \times 3 \times$ 8mm. Os espécimes foram polimerizados com LA por 30, 20 ou 10s e 40s com LH 
e então armazenados por $24 \mathrm{~h}$ a $37^{\circ} \mathrm{C}$ em um recipiente livre de luz. Realizou-se o teste Knoop com quatro medidas para cada espécime em profundidades de 0, 1 , 2, 3 e 4mm da superfície exposta. Não houve diferenças estatísticas na dureza de superfície para a resina de micropartícula ou híbrida considerando-se a fonte de luz e o tempo de exposição. Para a resina de micropartículas a 1, 2, 3 e 4mm de profundidade a LH 40s e LA 30s produziram valores de dureza comparáveis, o que foi muito superior aos valores de dureza encontrados para LA 20s e LH 10s. Na profundidade de $4 \mathrm{~mm}$, exposições de LH 40s resultaram em dureza maior do que LA 20s. Com LA 10s, a resina não foi polimerizada o suficiente para que a dureza pudesse ser determinada. A resina híbrida, na profundidade de $3 \mathrm{~mm}$, mostrou dureza comparável para LH 40s, LA 30s e LA 20s. Concluiu-se que a LH a 40s produziu uma polimerização comparável a do LA a 30s na resina de micropartícula e 20s na resina híbrida, representando uma economia de tempo de exposição de 30 - 50\% na polimerização com LA, em profundidades de $2 \mathrm{~mm}$.

FUJIBAYASHI et al. ${ }^{24}$, em 1998, avaliaram as características ópticas relacionandas ao grau de conversão e à profundidade de polimerização de dois aparelhos LED (Nichia Chemical Ind, Ltd., Tokushima) e um aparelho de luz halógena (Philips, Alemanha), todos ajustados para intensidade de $100 \mathrm{~mW} / \mathrm{cm}^{2}$. Com um radiômetro espectral (LI -1800 Licor, USA) mediu-se a distribuição no espectro de luz entre 300 e $800 \mathrm{~nm}$, sendo que o pico de irradiação localizoutse respectivamente em 444nm para L1 (LED de estrutura dupla), em 466nm para L2 (LED de estrutura simples) e em $484 \mathrm{~nm}$ para LH. O aproveitamento da intensidade de luz na faixa de absorção da CQ (de 410 a 500nm) foi de 84\% para 
L1; de $96 \%$ para L2 e de 94\% para LH. Os melhores valores de profundidade de polimerização $(\mathrm{L} 1=7,13 \mathrm{~mm}$, $\mathrm{L} 2=7,66 \mathrm{~mm}$ e $\mathrm{LH}=7,05)$ e grau de conversão foram conseguidos com o L2 (composto de 61 LEDs). Praticamente a totalidade de intensidade de luz emitida pelo $\mathrm{L} 2\left(100 \mathrm{~mW} / \mathrm{cm}^{2}\right)$ foi em uma faixa bastante estreita quando comparada aos outros aparelhos do estudo (L1 = 380 a 600nm; $\mathrm{L} 2=430$ a $550 \mathrm{~nm}$ e $\mathrm{LH}=380$ a $510 \mathrm{~nm}$ ), o que, segundo os autores, justifica os melhores resultados com L2. Então, a proporção de comprimentos de onda perto de 470nm, a mais efetiva para polimerização, é muito alta, mostrando que a luz irradiada pelo LED azul é efetiva na polimerização de resina composta. Os autores complementam o estudo explicando que, naquele momento, um único LED era envolvido em um modelo de acrílico de $5 \mathrm{~mm}$ de diâmetro podendo emitir baixa intensidade de luz por elemento, fazendo-se necessária a utilização de mais de um LED a fim de atingir a intensidade de luz suficiente para uma unidade de polimerização. Os autores sugerem a utilização de uma fonte de luz integrada que proporcione suficiente intensidade de luz e o aprimoramento da convergência de luz.

MILLS; JANDT; ASHWORTH ${ }^{41}$, em 1999, testaram a hipótese de que o LED poderia produzir uma igual profundidade de polimerização na resina composta, assim como um aparelho de LH ajustado para irradiação de $300 \mathrm{~mW} / \mathrm{cm}^{2}$. Os autores também determinaram a real potência destes aparelhos. Utilizaram-se as resinas Silux Plus cor U (partícula de 0,01-0,09 micrometro/40\% de partículas por vol), P50 cor U (partícula de 0.2-6 micrometros/77\% de partículas por vol) e Z100 MP cor A3,5 (partícula de 0.01-3,5 micrometros/ 66\% 
de partículas por vol), representando materiais usados rotineiramente em dentes anteriores e posteriores. Os tempos de polimerização foram os recomendados pelo fabricante: 40s, 60 s e 40 s para cada uma das três resinas respectivamente. Utilizaram-se os seguintes aparelhos: LH Coltolux 4 (Coltene/Whaledent Inc, Mahwah NJ, USA), com fonte de luz de $8 \mathrm{~mm}$ de diâmetro e um conjunto de 25 LEDs (Nichia Chemical Industries Ltd, Anan, Japão) com fonte de luz de $6 \mathrm{~mm}$ de diâmetro, tendo a potência de saída verificada pelo medidor de potência Coherent 210 (Coherent Ltd., Cambridge, UK). O espectro de luz dos aparelhos foi medido usando-se um espectro gráfico de imagem MS127i com um detector de irradiação Instaspec IV CCD (LOT Oriel, UK). Para confecção dos espécimes utilizoutse uma matriz de aço inoxidável contendo $4 \mathrm{~mm}$ de diâmetro e $6 \mathrm{~mm}$ de espessura. Verificou-se a profundidade de cura por meio de um penetrômetro com uma agulha de $0,5 \mathrm{~mm}$, com peso de $1250 \mathrm{~g}$. Os autores observaram que o fluxo espectral das unidades diferiu fortemente. O fluxo do LED ficou concentrado em uma banda bastante estreita do espectro, com pico em $460 \mathrm{~nm}$. O fluxo total em potência dos aparelhos, segundo o medidor científico foi, para o LED $82 \mathrm{~mW}$ e para LH 229mW. Na faixa de 410 - 500nm do espectro, o fluxo foi de $78 \mathrm{~mW}$ para o LED e 195mW para LH. Noventa e cinco por cento da potência irradiada pelo LED caiu na faixa de 410 - 500nm. Na conversão para densidade de potência (intensidade de luz irradiada pelo diâmetro da ponta ativa do aparelho em $\mathrm{mW} / \mathrm{cm}^{2}$ ) ocorre uma aparente mudança, já que o cálculo envolve o diâmetro da ponta ativa do aparelho (8mm para LH e $6 \mathrm{~mm}$ para LED), sendo a irradiação efetiva (na faixa de $410-500 \mathrm{~nm}$ ) de $276 \mathrm{~mW} / \mathrm{cm}^{2}$ para o LED e de $388 \mathrm{~mW} / \mathrm{cm}^{2}$ para LH. O LED apresentou maior irradiação na região do pico de absorção para 
a CQ (468nm) o que pode explicar a maior profundidade de cura observada para as amostras polimerizadas com LED. A luz azul em diferentes partes do espectro de absorção da $\mathrm{CQ}$ possui diferentes efetividades e aquela mais próxima do pico de absorção da mesma é mais eficaz na polimerização. A fonte de luz LED foi capaz de propiciar maior profundidade de cura para os três diferentes tipos de resina em comparação à fonte de LH ajustada por um radiômetro comercial em uma irradiação de $300 \mathrm{~mW} / \mathrm{cm}^{2}$. No entanto, os autores complementam que a profundidade de cura é apenas um dos muitos testes que podem ser aplicados para as resinas compostas fotopolimerizáveis. Outros testes mecânicos devem ser realizados a fim de determinar se a resina composta, polimerizada com LED comporta-se da mesma forma que a resina composta convencionalmente polimerizada.

PARK; CHAE; RAWLS ${ }^{51}$, em 1999, testaram o efeito sinérgico da combinação da CQ com o fotoiniciador fenil-propanodiona (PPD) com um novo fotoiniciador. Dezessete grupos de três espécimes cada foram testados com concentração de PPD e CQ variadas. O efeito da fotosensibilidade (CQ ou PPD) e a proporção $\mathrm{PPD} / \mathrm{CQ}$ no grau de conversão foram investigados por espectrofotometria de infravermelho (FTIR). Ambos, juntos, produziram um grau de conversão que excedeu aquele produzido pela mesma concentração de um deles sozinho. (PPD/CQ = 1:1 e 1:4). Numa concentração total acima de 1,8\% em peso, o grau de conversão é aumentado pelo PPD e diminuído pela CQ o que evidencia diferentes mecanismos para ambos. O PPD (410nm) e CQ (468nm) possuem diferentes comprimentos de onda resultando em tom amarelo mais claro 
para PPD. Portanto PPD é um fotoiniciador de valor potencial na redução de problemas de cor associados às resinas compostas fotopolimerizáveis e em combinação com a $\mathrm{CQ}$ age sinergicamente produzindo uma reação de foto iniciação mais eficiente, no entanto o aparelho fotopolimerizador deverá emitir luz de qualidade compatível com a sensibilidade deste fotoiniciador.

RUEGGEBERG56, em 1999, publica uma revisão sobre o processo de polimerização, variedades de aparelhos fotopolimerizadores existentes no mercado e as diferenças entre as filosofias pertinentes à polimerização. A tendência é que o rótulo da resina composta traga informações sobre a energia necessária para a polimerização. Da mesma forma, o aparelho fotopolimerizador deve indicar a intensidade de luz e comprimento de onda emitido. O espectro necessário para uma resina deve combinar com o espectro de luz emitido pelo aparelho, pois do contrário, não haverá fotopolimerização. O autor define um conceito sobre energia total de polimerização. A analogia é feita com um filme fotográfico, onde o tempo de exposição é variado de acordo com as condições de luz do ambiente e com a sensibilidade do filme a ser usado (a ASA ou o número ISO). Um filme mais sensível vai necessitar de tempos de exposição mais curtos em níveis menores de iluminação do que filmes de menor sensibilidade. Para calcular esta energia total, é necessário saber a intensidade da unidade fotopolimerizadora (em $\mathrm{mW} / \mathrm{cm}^{2}$ ) e a duração do tempo de exposição (em segundos). Considerando-se uma resina que necessite de uma exposição de 40s a $600 \mathrm{~mW} / \mathrm{cm}^{2}$ para propiciar adequada polimerização em $2 \mathrm{~mm}$ de profundidade, o total de energia concedida a este material é o produto de $40 \mathrm{~s} \times 600 \mathrm{~mW} / \mathrm{cm}^{2}$ ou 
$24000 \mathrm{~mJ} / \mathrm{cm}^{2}\left(24 \mathrm{~J} / \mathrm{cm}^{2}\right)$. Desta forma, qualquer combinação de exposição e intensidade que resulte em $24 \mathrm{~J} / \mathrm{cm}^{2}$ deve propiciar a mesma quantia de polimerização.

$\mathrm{SUH}^{68}$, em 1999, concordando com o novo conceito de energia total para polimerização de resinas, explica que a contração da resina composta induz a um estresse final na restauração quando o compósito encontra-se aderido à superfície do dente. A quantidade de estresse pode ser controlada pelo método de polimerização com atraso. O desenvolvimento de novos compósitos tem mudado as necessidades de energia para polimerização. A energia total requerida para uma ótima polimerização tem sido reduzida e a proporção na qual a energia é fornecida pode ter um forte efeito nas propriedades finais da restauração. Resinas compostas mais recentes podem empregar diferentes fotoiniciadores, fazendo com que o espectro de emissão da unidade fotopolimerizadora seja um importante fator para as propriedades finais da restauração. É necessário que os rótulos das resinas compostas contenham informações como: (1) indicações da energia total necessária; (2) especificações sobre a polimerização com atraso se necessário; e (3) o comprimento espectral necessário da luz emitida pela lâmpada fotopolimerizadora. O autor enfatiza que a densidade de energia total para ótima polimerização deve ser determinada.

JANDT et al..$^{30}$, em 2000, testaram a hipótese de que a profundidade de polimerização e resistência à compressão das resinas compostas, polimerizadas com LED e com LH, não difeririam significantemente. O segundo objetivo era caracterizar a irradiação e o espectro de luz emitido por ambas as fontes a fim de 
permitir comparações entre as mesmas. Empregou-se a resina Spectrum TPH nas cores A2 e A4, polimerizada por 40s com ambas as fontes. Os aparelhos usados foram um conjunto de 27 LEDs azuis (Nichia Chemical Ind. Ltd, Japão) com $6 \mathrm{~mm}$ de diâmetro da fonte de luz e o aparelho de LH Spectrum modelo $201 \mathrm{R}$ (Dentsply De Trey GmbH, Alemanha) com 9mm de diâmetro na fonte de luz. Foram verificados a potência de saída dos aparelhos, com medidor científico de potência (Coherent 210 Coherent Ltd Cambridge. UK) e o espectro de emissão, com o aparelho MS127I e o detector de irradiação IVCCD (LOT Oriel, Leatherhead, Surrey. UK). Desta forma mede-se a distribuição da intensidade de luz emitida através do espectro, preferivelmente ao que obtém com um radiômetro comercial, o qual mede a intensidade de luz emitida nos comprimentos de onda determinados pelo filtro do mesmo. Mediu-se a profundidade de polimerização em 10 amostras de cada cor, com $4 \mathrm{~mm}$ de diâmetro e $8 \mathrm{~mm}$ de espessura, por meio de um penetrômetro. Compararam-se os resultados usando o teste t-Student. A resistência à compressão foi determinada depois de 6 e 72 horas. A irradiação emitida foi de $755 \mathrm{~mW} / \mathrm{cm}^{2}$ e $350 \mathrm{~mW} / \mathrm{cm}^{2}$ para LH e LED respectivamente. O aparelho de LH apresentou uma extensa distribuição de irradiação no espectro, com pico em longos comprimentos de onda e uma extensa continuidade para região de comprimentos mais curtos, sendo que $95 \%$ da irradiação total estiveram entre $398 \mathrm{~nm}$ e $507 \mathrm{~nm}$ concentrando-se em $497 \mathrm{~nm}$. O LED, por outro lado, teve um pico único máximo em $465 \mathrm{~nm}$ com $95 \%$ de irradiação concentrada entre $438 \mathrm{~nm}$ e $501 \mathrm{~nm}$. Observando-se que, nesta região entre 450-470nm, a irradiação do LED foi quase duas vezes a do aparelho de LH. Os resultados mostraram que a LH polimerizou as resinas mais profundamente $(6,40 \mathrm{~mm} \mathrm{A2,5,19mm} \mathrm{A4),} \mathrm{do}$ 
que o LED $(5,33 \mathrm{~mm} \mathrm{A2,4,27mm} \mathrm{A4),} \mathrm{no} \mathrm{entanto,} \mathrm{segundo} \mathrm{o} \mathrm{fabricante} \mathrm{e} \mathrm{as}$ normas ISO 4049, ambas unidades polimerizaram os compósitos mais profundamente do que o necessário. A avaliação ANOVA a três critérios mostrou não haver diferenças significantes na resistência à compressão de amostras produzidas com LED ou LH. Encontraram-se significativas diferenças em resistência à compressão de amostras armazenadas por 6 e 72 horas e de amostras de diferentes cores, como confirmadas pelo teste ANOVA a três critérios. Apesar da grande diferença de intensidade de luz emitida entre os aparelhos, houve apenas uma pequena diferença na profundidade de polimerização resultante, sendo a resistência à compressão estatisticamente equivalente. Isto pode ser possivelmente explicado, segundo os autores, pela boa correlação entre o espectro de absorção da CQ e o espectro de luz emitido pelo LED. Com suas vantagens inerentes, o LED possui grande potencial de proporcionar boas propriedades às resinas compostas.

STAHL et al. ${ }^{67}$, em 2000, investigaram propriedades flexurais de três diferentes compósitos em três cores polimerizadas com LED ou LH e buscaram explicar, a efetividade do LED comparada ao aparelho de LH. Utilizou-se um aparelho de LH Spectrum LCU modelo 201 R (Dentsply De Trey GmbH, Konstanz, Germany) com fonte de luz de $9 \mathrm{~mm}$ de diâmetro e bulbo halógeno resfriado por ventilador com poder de consumo de 49W, irradiação de $755 \mathrm{~mW} / \mathrm{cm}^{2}$ e um aparelho tipo LED com 27 feixes (Nichia Chemical Industries Ltd., Anan, Japão) com fonte de luz de $6 \mathrm{~mm}$ de diâmetro com irradiação de $350 \mathrm{~mW} / \mathrm{cm}^{2}$. As resinas usadas foram: Spectrum TPH, cores A2 e A4 (Dentsply 
de Trey GmbH, Konstaz, Germany), Z100 cores A2 e A4 (3M Dental Products, St. Paul, MN USA) e Solitare, cores A2 e A3 (Heraeus Kulzer, Wehrheim, Germany). O tempo de ativação foi de 20s para resina Spectrum TPH/A2 e 40s para as demais resinas. Os espécimes com dimensões de $25 \mathrm{~mm} \times 2 \mathrm{~mm} \times 2 \mathrm{~mm}$ foram armazenados por 24 horas em água antes dos testes, sendo dez para cada cor. A velocidade média do teste foi de $0,75 \mathrm{~mm} / \mathrm{min}$ até o ponto de fratura do espécime. Os resultados da resistência flexural foram analisados com o teste ANOVA a três critérios com 95\% de confiança, tendo como variáveis as unidades, os compósitos e as cores dos compósitos. Foram realizados múltiplos testes (Fisher's LSD) com 95\% de confiança a fim de identificar os grupos homogêneos. Todos os materiais, exceto a Solitaire cor A3, preencheram os requisitos ISO 4049 em termos de resistência flexural, quando polimerizados com LED e LH. No entanto, a resistência flexural de todos os espécimes polimerizados com $\mathrm{LH}$ foi estatisticamente maior do que os polimerizados com o LED. Os autores demonstram uma fórmula que pode ajudar a explicar a efetividade do LED em relação à LH diante de diferenças de intensidades de luz tão significativas entre os aparelhos. O potencial de polimerização foi considerado proporcional ao número de fótons disponíveis para absorção (espectro emitido) e a probabilidade de que estes serão absorvidos (espectro de absorção) considerando também a banda de extensão no espectro para cada aparelho e relacionando com as intensidades de luz. Desta forma o LED teve $92 \%$ do rendimento do aparelho de LH. No entanto, os autores mencionam que melhor do que somente comparar irradiação dos aparelhos é comparar as propriedades mecânicas de resinas compostas polimerizadas com LED ou LH, visto que apesar das diferentes 
intensidades de luz apresentadas, as médias de resistência flexural obtidas com o aparelho LED foram satisfatórias. Isto pode ser explicado pela correlação entre o espectro de absorção da CQ e o espectro de emissão do LED.

SEABRA ${ }^{61}$, em 2000, avaliou a profundidade de polimerização de resinas de alta densidade e sua relação com diferentes tempos de exposição e polimerização através do esmalte dentário. Neste sentido, foram analisadas as resinas Alert (A), Solitaire (So), Surefill (Su) e a resina híbrida Z100 (Z), sendo utilizada como controle. Empregou-se uma matriz cilíndrica de teflon branco com $1 \mathrm{~cm}$ de espessura $\times 0,5 \mathrm{~cm}$ de diâmetro para obtenção dos espécimes. Uma lamínula de vidro de 0,2mm de espessura foi interposta entre a matriz e a fonte de luz (Curing Light $2500-3 \mathrm{M}$ ) com ou sem a faceta de esmalte, de $1,6 \mathrm{~mm}$ de espessura, seguida de polimerização por 40 e 80s. Realizou-se o teste de dureza Barcol e os dados foram submetidos à análise de variância a três critérios e teste de Tukey. Observourse diferença estatisticamente significante para as variáveis material, tempo de exposição à luz e interferência do esmalte, exceto para as condições com e sem interferência de estrutura dentária e exposição por 80s (entre as resinas Z100 e SureFill) e com interferência de estrutura dentária e exposição por 40s (entre as resinas Z100 e SureFill como também entre as resinas Surefill e Alert). Os resultados indicaram que a interposição do esmalte e o tempo de exposição à luz interferem na profundidade de polimerização, podendo afetar o grau de polimerização mínimo estabelecido pelos fabricantes.

KNEZEVIC et al. ${ }^{31}$, em 2001, compararam o grau de conversão (GC) e o aumento de temperatura de quatro resinas compostas híbridas (Tetric Ceram, 
Pertac II, Valuxz Plus e Degufill Mineral) durante exposição à luz convencional halógena dos seguintes aparelhos: Heliolux GTE com $600 \mathrm{mw} / \mathrm{cm}^{2}$ de intensidade de luz por 40s; Elipar Highlight soft-start (baixa intensidade de luz inicial) com $100 \mathrm{~mW} / \mathrm{cm}^{2}$ por 10 s e com $700 \mathrm{~mW} / \mathrm{cm}^{2}$ por 30 s e exposição à luz de um conjunto de 16 LEDs de mínima intensidade $\left(12 \mathrm{mw} / \mathrm{cm}^{2}\right)$ na superfície e com $1 \mathrm{~mm}$ de profundidade. Os autores observaram que o maior grau de conversão foi obtido na resina Pertac II por ambas unidades de luz halógena $(70,39 \pm 1,73$ na superfície, 67,33 \pm 3,14 em 1mm para Heliolux GTE; 68,34 \pm 1,05 na superfície e $68,45 \pm 1,08$ em $1 \mathrm{~mm}$ de espessura para o Elipar Highlight) e LED $(58,89 \pm 1,30$ na superfície e 59,00 $\pm 1,52 \mathrm{em} 1 \mathrm{~mm}$ de espessura). Perante estes valores, os autores concluíram que a presente diferença no GC entre as unidades de luz halógena e a de LED não é tão significante em virtude da considerável diferença de intensidades de luz das mesmas (luz halógena 66 vezes mais potente). Quanto à temperatura, o maior aumento ocorreu com a polimerização de amostras com o Heliolux GTE na superfície e em $1 \mathrm{~mm}$. Um significativo menor aumento de temperatura (duas vezes menor) ocorreu na irradiacão com o LED comparado com ambas unidades de luz halógena. O aparelho LED mostroutse uma promissora alternativa para fotopolimeirzação, principalmente no que se refere ao aumento de temperatura da resina composta, entretanto para assegurar suficiente intensidade de luz e melhorar os valores de polimerização são necessários o emprego de mais unidades de diodo e a maior concentração do feixe de luz. 
KURACHI et al. ${ }^{33}$, em 2001, avaliaram a dureza de uma resina composta polimerizada por dois (L2 - $\left.25 \mathrm{~mW} / \mathrm{cm}^{2}\right)$, três $\left(\mathrm{L} 3-34 \mathrm{~mW} / \mathrm{cm}^{2}\right)$, quatro (L4 $\left.46 \mathrm{~mW} / \mathrm{cm}^{2}\right)$, cinco $\left(\mathrm{L} 5-68 \mathrm{~mW} / \mathrm{cm}^{2}\right)$ ou seis $\left(\mathrm{L} 6-79 \mathrm{~mW} / \mathrm{cm}^{2}\right)$ LEDs azuis (Nichia Chemical Ind, 2000mcd, Japão) e compararam com a unidade de LH (K\&M, 200R, São Carlos, Brasil) de $475 \mathrm{~mW} / \mathrm{cm}^{2}$. As medidas de potência foram feitas por um medidor científico (Field Master, Coherent, USA). A resina composta (Z100 cor A3) foi polimerizada por 20, 40, 60, 120 e 180s com cada base de LEDs e por 40 s com a LH. Prepararam-se cinco amostras de resina composta para cada grupo, nas espessuras de 0,35, 1,25 e 1,8mm. Realizou-se a avaliação da dureza na superfície não irradiada, por meio de três endentações para cada amostra. Todas as amostras polimerizadas pelo LED apresentaram dureza inferior quando comparadas à LH no tempo típico de 40s. A unidade L6 foi a mais eficiente, no entanto tempos de exposição mais longos ou camadas mais finas de resina foram necessárias. Usando-se o L6 com 40s de exposição para incrementos de $0,7 \mathrm{~mm}$ de espessura o número de dureza Vickers 100 foi obtido. Apesar da diferença de irradiação quando comparado com a LH, o LED mostrout se uma promissora alternativa na polimerização de resinas compostas, principalmente porque quase a totalidade da energia emitida esteve dentro da extensão ideal de absorção para a CQ.

MEDEIROS ${ }^{39}$, em 2001, apresenta um estudo sistemático de comparação da microdureza Vickers, obtida em espécimes polimerizados com três diferentes fontes de luz, a fim de determinar uma relação de tempo de exposição e profundidade de polimerização para o dispositivo experimental à base de LEDs e 
sua perspectiva para aplicações clínicas. A resina composta Z100 cor A3 (3M do Brasil) foi inserida em incremento único em uma matriz de aço inoxidável, com cilindros de $8 \mathrm{~mm}$ de diâmetro em duas profundidades: 0,7mm e 2,0 mm. Na base da parte cilíndrica uma tira de poliéster foi acomodada para permitir uma maior lisura na superfície oposta à iluminada. Utilizaram-se os aparelhos $\mathrm{LH}-(<200 \mathrm{R}$, $\mathrm{K} \& \mathrm{M}$, Brasil ) com potência de $350 \mathrm{~mW}$ e intensidade de $700 \mathrm{~mW} / \mathrm{cm}^{2}$; laser de argônio (LA), linha 488nm, (INNOVA 100, Coherent, EUA) com potência de 500 $\mathrm{mW}$ e intensidade de $1 \mathrm{~W} / \mathrm{cm}^{2}$ e um dispositivo LED em caráter experimental com potência média de $50 \mathrm{~mW}$ e intensidade aproximada de $100 \mathrm{~mW} / \mathrm{cm}^{2}$. Realizourse a analise estatística dos dados obtidos por meio de análise de variância (ANOVA) e teste de Tukey com 5\% de significância. Os valores de dureza obtidos na face diretamente iluminada (topo) mostraram equivalência entre as três fontes de luz para polimerização, com variação inferior a 10\%, sendo estes valores superiores àqueles obtidos a 0,7 e 2,0 mm de profundidade. Para a espessura de $0,7 \mathrm{~mm}$, a LH, o LED e o LA obtiveram os mesmos valores de dureza Vickers, utilizando-se os tempos de exposição de 40s, 40s e 10s, respectivamente. Para espécimes com espessura de 2,0mm um tempo de exposição de 40 s foi necessário para obtenção de valores de microdureza equivalentes aos obtidos com a $\mathrm{LH}$ em 40 s ou com o LA por 10s. Recomenda-se a utilização de 60 s de exposição para incrementos de $2 \mathrm{~mm}$ de espessura com os dispositivos a base de LED.

MITTON; WILSON ${ }^{42}$, em 2001, com o objetivo de complementar as pesquisas sobre unidades de emissão de luz e desenvolver um protocolo para uso e cuidados rotineiros das unidades de polimerização, investigaram os 
cuidados de manutenção destes aparelhos na rotina dos consultórios odontológicos em uma cidade do noroeste da Inglaterra. A pesquisa constituiurse de entrevista e análise dos aparelhos. Dos 77 questionários, 54 foram respondidos completamente, incluindo informações sobre 164 aparelhos, dos quais 100 foram examinados. Dentre estes aparelhos, 28 apresentavam intensidade de luz inadequada (menor que $300 \mathrm{~mW} / \mathrm{cm}^{2}$ ), em $47,47 \%$ havia problemas, 35\% apresentavam quantidades variáveis de material aderente à fonte de luz. Concluiurse que os profissionais necessitavam ampliar seus conhecimentos sobre os aparelhos polimerizadores e, ao final da pesquisa, distribuiu-se um guia de cuidados e manutenção das unidades de luz.

PARK; KREJCI; LUTZ ${ }^{52}$, em 2002, avaliaram a efetividade do fotopolimerizador de arco de plasma (PAC) em relação ao convencional de LH por meio do teste de microdureza de superfície e em profundidade, utilizando-se as resinas compostas Z100 e Tetric Ceram. Os espécimes com espessura de $2 \mathrm{~mm}$ foram polimerizados por 3s, 6s e 12s pelo aparelho Apollo 95E (PAC) e por 30s e 60s, pelo aparelho Optilux 500 (LH). Os espécimes com espessura de 3mm foram polimerizados por 6s, 12s e 18s com o Apollo 95E e por 30 e 60s com o Optilux 500. Realizourse o teste de microdureza Vickers nas superfícies de topo e de base dos 20 espécimes de cada grupo. Não se verificaram diferenças estatísticas significantes entre os grupos para a superfície de topo. Entretanto a superfície de base quando polimerizada com o Apollo 95E por 3s, como recomendado pelo fabricante, apresentou valores de microdureza inferiores aos da superfície de topo e não polimerizou suficientemente. Os autores concluíram que, quando 
comparado à unidade de LH, o PAC não polimerizou efetivamente a superfície da base em espessuras superiores a $2 \mathrm{~mm}$, mesmo com o tempo de ativação recomendado pelo fabricante (3s).

FRANCO; NAVARRO ${ }^{21}$, em 2002, avaliaram a profundidade de polimerização de diferentes resinas compostas de mesmo matiz, mas com diferentes cromas. Para padronização dos corpos de prova utilizourse uma matriz de aço inoxidável bipartida com $10 \mathrm{~mm}$ de altura e $5 \mathrm{~mm}$ de diâmetro, confeccionando-se cinco espécimes para cada condição experimental. Testourse um aparelho LED experimental (no2) em comparação aos aparelhos de luz halógena ULTRALUX (Dabi Atlante, Lote 10505) e Curing Light 2500 (3M, Lote 3017518) nos tempos de ativação de 20s e 40s. A fim de averiguar a intensidade de luz dos aparelhos utilizou-se um radiômetro comercial (Curing Fadiometer Model 100 P/N - 10503/ Demetron Research Corp). Utilizou-se uma faceta de esmalte dentário com espessura de 1,5mm, com a finalidade de avaliar a possível influência na difusão da luz. Imediatamente após a polimerização dos espécimes e remoção da matriz, removeurse a porção de resina não polimerizada da face oposta à fonte de luz por meio de raspagem com instrumento manual e a mesma foi planificada. Os espécimes foram levados a um dispositivo desenvolvido pelo autor, o qual permite avaliar a resistência à penetração na superfície oposta à fonte de luz. Depois da remoção do espécime do dispositivo, fez-se a leitura do material polimerizado com espessímetro. O sistema LED apresentourse viável para polimerização das diferentes resinas, sendo que o tempo de 40 s elevou a profundidade de polimerização das diferentes marcas comerciais de resina 
composta para valores que se aproximam dos observados com os aparelhos de LH no tempo de 20s. A interposição da faceta de esmalte reduziu de forma geral a profundidade de polimerização independente do tipo de fonte de luz. Face aos menores valores de profundidade de polimerização observados com o LED, um tempo mínimo de 40s deve ser estabelecido para polimerização através da estrutura dentária. Não obstante as variações na profundidade de polimerização, os valores apresentados superam a espessura de 1 a $1,5 \mathrm{~mm}$ recomendada na prática clínica tanto para sistema de LH com para o sistema LED.

SANTOS; EL-MOWAFY; RUBO ${ }^{59}$, em 2002, pesquisaram os efeitos da intensidade de luz do aparelho de LH de quartzo tungstênio (QHT) Visilux 2 (3M) a $550 \mathrm{~mW} / \mathrm{cm}^{2}$; Optilux 501 (SDS/Kerr) a $1,360 \mathrm{~mW} / \mathrm{cm}^{2}$ e do aparelho tipo LED Elipar Free Light (3M ESPE) a $320 \mathrm{~mW} / \mathrm{cm}^{2}$ no número de dureza Knoop (NDK) do cimento resinoso Rely X (3M ESPE). As amostras foram confeccionadas com espaçadores de porcelana e de resina composta com 3mm de espessura e as mesmas foram polimerizadas por 40 s. Observourse que a fotopolimerização com $1360 \mathrm{~mW} / \mathrm{cm}^{2}$ resultou em um significativo aumento do NDK em todas as situações estudadas. Apesar da diferença na intensidade de luz entre o aparelho de luz halógena Visilux $2\left(550 \mathrm{~mW} / \mathrm{cm}^{2}\right)$ e o aparelho LED Elipar Free Light $\left(320 \mathrm{~mW} / \mathrm{cm}^{2}\right)$, nenhuma diferença estatística foi encontrada no NDK das amostras fotopolimerizadas através de $3 \mathrm{~mm}$ de resina com estas unidades.

DUNN; VUSH ${ }^{14}$, em 2002, compararam a dureza de superfície de topo e de base da resina composta híbrida Filtek Z-250 na cor A1 (3M St. Paul, Minn.) e da resina composta de micropartícula Renamel cor A1 (Cosmedent Chicago), sendo 
20 espécimes de cada, feitos em modelos de polímero de acetato (Delrin, E.I. DuPont de Nemours \& Co., Wilmington, Del.) de $8 \mathrm{~mm} \times 2 \mathrm{~mm}$, polimerizando-os com duas unidades de LH Optilux $400\left(900 \mathrm{~mW} / \mathrm{cm}^{2}\right)$ e Optilux $501\left(1030 \mathrm{~mW} / \mathrm{cm}^{2}\right.$ - Demetron Research Corp., Danbury, Conn.) e dois aparelhos LED disponíveis comercialmente (LumaCure $150 \mathrm{~mW} / \mathrm{cm}^{2}$, LumaLite Inc., Spring Valley, Calif.; VersaLux $150 \mathrm{~mW} / \mathrm{cm}^{2}$, Centrix, Shelton, Conn.) com sete LEDs cada. As intensidades de luz dos aparelhos foram checadas prévia e durante o experimento com radiômetro comercial (Demetron 100, demetron Research Corp.) A duração de exposição foi de 40 s e após $24 \mathrm{~h}$ o teste de dureza por indentação com Knoop (M-400-G2, LECO, St. Joseph, Mich.) foi efetuado com carga de $100 \mathrm{~g}$ e 10 s de espera com três repetições em superfície de topo e de base seguido do cálculo das médias. Para o cálculo de profundidade de polimerização dividiu-se a dureza da base pela do topo e multiplicourse o resultado por 100. Usourse o teste variância ANOVA a dois critérios para testar diferenças de dureza de superfície com respeito ao tipo de luz e tipo de resina composta e para testar a interação entre os grupos. Quando se compararam os tipos de resina composta as diferenças foram significantes, sendo que a resina híbrida apresentou maior dureza de superfície de topo e de base para todos os aparelhos. As unidades de LH produziram maior dureza de superfície de topo e de base do que os LEDs. Comparando-se todas as combinações de tipo de resina e luz, detectaram-se diferenças significantes para todas as superfícies mas não para todas porcentagens de profundidade de polimerização. Ou seja, apesar dos valores de dureza de superfície para ambos os tipos de resina serem inferiores para LED em relação à LH os resultados da porcentagem de profundidade de 
cura sozinhos não foram capazes de identificar isto. O autor aponta que a intensidade de luz dos aparelhos tipo LED deve ser aumentada e sugere estudos que possam comparar grau de conversão, propriedades físicas e mecânicas das resinas após polimerização com estes aparelhos.

JANA; SANTOS; CORRÊA ${ }^{29}$, em 2002, compararam a eficiência da fotoativação com LED em relação aos aparelhos de LH por meio de valores de resistência flexural. Os autores prepararam 10 corpos de prova em forma de barra (ISO 4049) em matriz de aço inoxidável, com as resinas Z250/3M, A110/3M, Tetric Ceram/Vivadent (TC), Solitaire/Heraeus Kulzer (ST), Durafill/Heraeus Kulzer (DF), Esthet-X/Dentsply (EX), Definite/Degussa (DT) na cor A2. A fotoativação com LED (Ultrablue, DMC) e com luz halógena (Optilux 401 Demetron) foi executada por 40s. Após a fotoativação, os espécimes foram mantidos em água destilada a $37^{\circ} \mathrm{C}$ por $24 \mathrm{~h}$. Realizourse o teste de flexão em três pontos em máquina universal de teste Instron 4442, com a velocidade de 0,5mm/min. Após a ruptura, os valores $(\mathrm{MPa})$ foram submetidos à análise de variância e teste de Tukey. A resina Z 250 obteve os maiores valores para o LED -149 (12,5) e LH 145 - (11,2). Para TC, EX, ST, DF, A 110 e DT, não houve diferença estatística entre as médias obtidas com o aparelho de LH e o LED. Porém quando ativada por LED a Definite mostrou menor resistência. As resinas A110 e Durafill obtiveram os menores valores. Concluindo-se que, para as resinas testadas a fotoativação com LED foi tão eficiente quanto a com LH. Apenas na resina Definite, onde há fotoiniciadores de absorção espectral próximo ao ultravioleta a fotoativação com LED não foi efetiva. 
LOPES et al..$^{35}$, em 2002, avaliaram a resistência à compressão diametral (RCD) das resinas: de micropartícula A110-3M e híbrida TPH-Dentsply na cor A2, usando três tipos de fonte de luz: LED $130 \mathrm{~mW} / \mathrm{cm}^{2}$ (ULtraLED, Dabi Atlante ${ }^{74}$ ), LH $300 \mathrm{~mW} / \mathrm{cm}^{2}$ (Ultralux, Dabi Atlante) e LH $600 \mathrm{~mW} / \mathrm{cm}^{2}$ (Optilux 401 Demetron). Confeccionaram-se cilindros de resina composta a partir de uma matriz metálica bipartida com $4 \mathrm{~mm}$ de diâmetro e $2 \mathrm{~mm}$ de altura. $\mathrm{O}$ cilindro foi totalmente preenchido com a resina composta e uma matriz de poliéster foi superposta para a fotopolimerização por 20 e 40s. Os cilindros foram armazenados em água e posicionados horizontalmente entre duas bases metálicas acopladas em uma máquina universal de testes (Instron 4444). Os dados foram analisados com ANOVA a um critério e Scheffé. As médias de RCD para A110 variaram de 22,0 a 24,6 Mpa, não havendo diferença entre os fotopolimerizadores e os dois tempos testados. A TPH fotopolimerizada pelo aparelho LED por 20s apresentou RCD menor (29,4 MPa) do que quando fotopolimerizada pelos aparelhos de $\mathrm{LH}$ testados (40,8 e 41,6 MPa). No entanto a duplicação deste tempo de fotopolimerização anulou esta diferença $(42,1 ; \quad 43,6$ e $41,0 \quad \mathrm{MPa}$, respectivamente). O fotopolimerizador LED testado propicia adequada RDC da resina híbrida polimerizada por 40s e da resina micropartícula por apenas 20 s.

NOMURA et al. ${ }^{49}$, em 2002, avaliaram as características do polímero formado pela polimerização com LED e com LH por meio de análise térmica de duas resinas experimentais, cujo monômero base era uma mistura de Bis-GMA e TEGDMA (60:40 em peso), com 0,5\% CQ/DMPT ou CQ/DMAEMA, após 40s de ativação. Examinou-se a estrutura interna da resina composta por meio de 
escaneamento diferencial calorimétrico (DSC) e o valor de dureza Knoop (KHN). A energia de ativação calculada para os espécimes polimerizados por LED foi maior do que $220 \mathrm{~kJ} / \mathrm{mol}$; para os espécimes polimerizados por $\mathrm{LH}$, foi menor que $192 \mathrm{~kJ} / \mathrm{mol}$. O KHN e grau de polimerização foram maiores para o LED, assim como estruturas tridimensionais mais estáveis foram obtidas com este aparelho. A conversão de ligações duplas dentro das amostras de polímeros não pode ser medida facilmente de forma direta, no entanto propriedades mecânicas são indicadores indiretos do grau de polimerização. A correlação entre as características térmicas e mecânicas das estruturas internas dos espécimes foi feita por meio da análise da energia necessária para ativar a decomposição da amostra e do KHN respectivamente. Os exemplares que necessitavam de maiores energias para a decomposição também possuíam maiores KHNs. A necessidade de maior energia de decomposição sugere maior grau de polimerização e maior número de ligações cruzadas. Os autores explicam a melhor performance da unidade LED comparada a de LH devido ao comprimento de onda emitido com pico em 470nm, coincidente com a curva de absorção da CQ (390-510nm).

PIMENTEL et al. ${ }^{55}$, em 2002, ao testar a espessura de resina polimerizada (Filtek Z250) pelo aparelho de LH Optilux/Demetron e pelo LED-Ultrablue/DMC, usaram tempos de 20 s e 40 s em incremento único, sendo que os corpos de prova foram confeccionados em matriz de aço com $3 \mathrm{~mm}$ de diâmetro e $6 \mathrm{~mm}$ de espessura. Foram confeccionados vinte espécimes (cinco para cada combinação de tempo e aparelhos) e para cada amostra, calculou-se a média de quatro 
aferições com micrômetro (Starrett/Brasil $\mathrm{n}^{\circ}$ 436-25mm). O aparelho de LH apresentou melhor penetração de luz do que o LED independente do tempo, na espessura de $6 \mathrm{~mm}$.

TOLOSA et $\mathrm{al}^{72}$, em 2002, avaliaram a resistência à tração diametral de três resinas compostas, de micropartícula (Filtek A110 - 3M); híbrida (Charisma Heraeus Kulzer); compactável (Filtek P60 - 3M), todas na cor A3, comparando a unidade de LH (Degulux- Degussa) com uma unidade LED (Ultrablue- DMC). As amostras foram confeccionadas utilizando-se uma matriz de teflon medindo $3 \mathrm{~mm}$ de profundidade e $6 \mathrm{~mm}$ de diâmetro interno, onde os compósitos foram inseridos em dois incrementos e fotoativados por 20s cada. Depois de armazenados por 7 dias em água destilada, a $37^{\circ} \mathrm{C}$ num recipiente escuro, realizou-se o teste e a análise de variância considerando os fatores material e fotopolimerizador. A análise mostrou efeito estatístico significante apenas para material sendo que a resina compactável $\mathrm{P} 60$ apresentou a maior média de resistência à tração diametral. As fontes fotoativadoras apresentaram o mesmo comportamento.

VIEIRA; BERNARDON; LOPES ${ }^{77}$, em 2002, avaliaram a profundidade de cura das resinas compostas micro-híbridas P. Prodigy-Kerr e Filtek Z250-3M com dois aparelhos fotopolimerizadores: LH (H.Ultralux - DabiAtlante) e LED (L.UltraLED-DabiAtlante). Foram confeccionados cilindros de resina composta a partir de uma matriz metálica bipartida com $4 \mathrm{~mm}$ diâmetro e $6 \mathrm{~mm}$ de altura. Cada resina composta foi inserida até o completo preenchimento do cilindro $(n=6)$. Posicionou-se uma matriz de poliéster sobre a resina composta e realizou-se a fotopolimerização durante 10, 15, 20 e 40s. Em seguida, realizou-se ao "teste de 
raspagem" com uma cureta afiada. A espessura do remanescente do cilindro foi medida com um espessímetro e o valor dividido por dois para a determinação da profundidade de polimerização. Os dados foram analisados com ANOVA a três critérios. Não houve diferença significativa na profundidade de cura entre os diferentes aparelhos e entre as resinas testadas. Concluindo-se que os aparelhos fotopolimerizadores testados (LED e LH) propiciaram níveis similares de polimerização das resinas compostas micro-híbridas.

VINHA et al. ${ }^{78}$, em 2002, avaliaram a profundidade de polimerização de cinco marcas comerciais de resinas compostas (P60 - 3M; Z100 - 3M; Charisma Heraeus Kulzer; Alert - Jeneric Pentron; Surfill - Heraus Kulzer) quando polimerizadas por LH e LED. Obtiveram-se cinco corpos de prova de cada material a partir de matriz de policarbonato preto de alta resistência, composta de duas partes, uma porção plana e outra contendo uma cavidade preparada com as seguintes dimensões: $7 \mathrm{~mm}$ de profundidade, $3 \mathrm{~mm}$ de altura e $4 \mathrm{~mm}$ de largura. As amostras foram polimerizadas por LH (Ultralux -DabiAtlante) durante 40s e luz de emissão de diodo (UltraLED Dabi Atlante) por 25 e 50s e submetidas à análise de microdureza superficial com carga de $5 \mathrm{~N}$ por um tempo de $20 \mathrm{~s}$. Os resultados indicaram que os valores médios de microdureza superficial foram maiores para os materiais fotopolimerizados por LED durante 25 s e 50 s, quando comparados aos materiais polimerizados por LH durante 40s. Concluiu-se que o LED permite a fotopolimerização adequada das resinas compostas em um tempo menor do que o necessário para a fotopolimerização com LH. 
GAUDET; BURGESS; LSUHSC et al. ${ }^{25}$, em 2002, avaliaram a profundidade de polimerização do LED Luxomax e Free Light em comparação com um aparelho de LH Optilux 501. Prepararam-se espécimes retangulares, com $8 \mathrm{~mm}$ de profundidade e $4 \mathrm{~mm}$ de largura, com as resinas compostas Synergy, Sculpt-It ou Z250 cor A2 e os mesmos foram polimerizados por 20s. As medidas de dureza Vickers foram tomadas no topo e lados do retângulo a cada milímetro em direção à resina não curada. As variáveis: tempo de exposição, compósito e unidade de luz foram significantes. O aparelho de LH obteve profundidades de cura significativamente maiores do que o Luxomax. Concluiu-se que a maioria dos LED polimerizou $2 \mathrm{~mm}$ de incrementos de compósito, porém apresentaram menores profundidades de polimerização em relação ao aparelho de LH.

FAY; LU; POWERS ${ }^{17}$, em 2002, avaliaram propriedades mecânicas de uma resina composta e um agente adesivo polimerizados com LED (Elipar FreeLight/3M ESPE) e com LH (Elipar TriLight/3M ESPE). As resinas foram Filtek Z250 (3M ESPE) e Single Bond (3M ESPE). Avaliaram-se a resistência flexural (RF) e o módulo de flexão em espécimes com dimensões de $2 \mathrm{~mm} \times 2 \mathrm{~mm} X$ 25mm após polimerização por intervalos de 20s por lado. Da mesma forma a resistência à compressão $(\mathrm{RC})$ e módulo de compressão $(\mathrm{MC})$ foram avaliados em espécimes com dimensões de $4 \mathrm{~mm}$ X 8mm após polimerização por 20s por lado. Utilizourse a máquina Instron, com velocidade média de $0,5 \mathrm{~mm} / \mathrm{min}$, para execução do teste. Também se avaliou a profundidade de cura com espécimes de 0,5 a $5 \mathrm{~mm}$ de espessura polimerizados por $20 \mathrm{~s}$, por meio de medidas de dureza Barcol. Não se observaram diferenças significativas nas propriedades dos 
espécimes obtidos com os diferentes aparelhos. Concluindo-se que a resina composta polimerizada com LED e LH apresentou as mesmas propriedades.

TONIOLI et al. ${ }^{73}$, em 2002, compararam a profundidade de polimerização relativa do LED, lâmpada de quartzo-tungstênio e arco plasma em diferentes tempos de exposição, por meio do teste de microdureza. O aparelho LED (Elipar FreeLight, 3M ESPE) foi avaliado nos tempos de exposição de 20, 30 e 40s. Os aparelhos de arco de plasma foram avaliados da seguinte forma: Virtuoso, ativado durante 3, 5, 7 e 9s e Apollo 95E durante 3s e 6s (3s - 3s atraso - 3s). Os aparelhos convencionais Demetron 501 (Sybron/Kerr), nas técnicas Boost 10s e Ramp 15s e o Elipar TriLight (ET, ESPE) ativado por 40s serviu de controle. Cilindros que continham a resina $Z-100$ na cor A2 ( $n=5 /$ grupo) foram fotopolimerizados por um lado. Os moldes então foram seccionados, polidos e quatro medidas Knoop (NDK) foram obtidas a $0,5 \mathrm{~mm}$ de profundidade incremental da superfície exposta à luz em direção à profundidade não testada $(0,5 \mathrm{~kg}$ por 15s). Comparou-se o NDK a cada profundidade usando-se o procedimento não paramétrico Kruskal Wallis. Os resultados mostraram que todos os testes para diferenças entre aparelhos/tempos de exposição foram altamente significantes. Concluiu-se que o LED ativado por 30s, 40s e a técnica Ramp 15s foram equivalentes ao aparelho de quartzo-tungstênio controle em todas as profundidades. O aparelho de arco plasma em tempos menores que $7 \mathrm{~s}$ resultou em significante menor NDK nas profundidades de 2,0 e $3,0 \mathrm{~mm}$ em relação ao Trilight. Para o LED Elipar Free Light (30s e/ou 40s) e Optilux 501 (15s no modo 
escalonado) encontraram-se resultados de polimerização análogos ao grupo controle.

PFEIFER et al. ${ }^{54}$, em 2002, realizaram um estudo in vitro para examinar a eficiência de diferentes métodos de polimerização pela determinação da dureza Vickers de resinas compostas com diferentes cores. Confeccionaram-se quarenta restaurações oclusais cilíndricas em resina composta (Tetric Ceram - Vivadent), em molares humanos cortados, com dimensões de $3 \mathrm{~mm} \times 3,5 \mathrm{~mm}$ de espessura, nas cores A1 e D3, com margens localizadas em esmalte. Dez espécimes para cada grupo foram polimerizados em incremento único, desta forma distribuídos: (1) fotopolimerizados com uma unidade de LH (Elipar TriLight - 3M ESPE) ou (2) fotopolimerizados com um aparelho de diodo emissor de luz (Elipar FreeLight 3M ESPE). Os espécimes foram armazenados em água deionizada em escuro absoluto por $24 \mathrm{~h}$ a $37^{\circ} \mathrm{C}$. Após este período, os espécimes foram cortados usando-se uma serra de diamante de baixa velocidade e determinourse o número de dureza Vickers (NDV) a 3mm de profundidade. Para análise estatística utilizouse o teste Mann-Whitney-U. Os autores observaram que o uso do Elipar FreeLight resultou em um NDV significativamente maior $(71,3)$ do que o Elipar TriLight $(63,4)$ para a cor A1. Com a cor mais escura, os métodos de polimerização não foram significativamente diferentes entre si (59,7 e 61,5 respectivamente). O NDV da cor mais clara A1 $(71,3)$ comparado ao da cor mais escura D3 $(59,7)$ foi significativamente mais alto com Elipar Free Light. No entanto, não houve diferenças significantes no NDV de restaurações com diferentes cores usando o Elipar TriLight (63,4 e 61,5 respectivamente). Os autores concluíram que a 
eficiência da polimerização de restaurações de resina composta com diferentes cores usando o LED foi igual ou melhor do que a polimerização com a luz halógena convencional.

PALMER et al. ${ }^{50}$, em 2002, compararam o desempenho de quatro diferentes unidades fotopolimerizadoras, sendo: 1. LED (CoolBlu); 2. Convencional de LH (Optilux 401); 3. LH rápida (Optilux 501) e 4.Plasma Arc (Power PAC). Potência, intensidade e espectro foram medidos usando-se um detector de potência (Molectron PM3), um radiômetro (Spring Health Light Meter UK) e um espectrômetro (International Light 587). A temperatura in vitro foi medida por meio da fotopolimerização do Vitrebond Liner (3M) colocado a 0,5 mm da polpa em um preparo MOD de um molar extraído, mantido em um banho de água circulante a $37^{\circ} \mathrm{C}$. $\mathrm{O}$ tempo de polimerização foi determinado através do teste de dureza Barcol de cinco restaurações com dimensões de $2 \mathrm{~mm}$ de espessura e $5 \mathrm{~mm}$ de diâmetro. A polimerização foi definida como $90 \%$ da dureza da superfície em $2 \mathrm{~mm}$ de espessura. A análise estatística foi feita usando-se GLM e o teste de Tukey. Os resultados indicaram que o LED testado apresentou menor potência (1. $116 \mathrm{~mW}$; 2. $468 \mathrm{~mW}$; 3. $424 \mathrm{~mW}$ e $4.960 \mathrm{~mW})$; menor intensidade de luz (1. $280 \mathrm{~mW} / \mathrm{cm}^{2} ; 2.620 \mathrm{~mW} / \mathrm{cm}^{2} ; 3.820 \mathrm{mWcm}{ }^{2}$ e $\left.4.980 \mathrm{~mW} / \mathrm{cm}^{2}\right)$; espectro de emissão mais estreito (1. $430-515 \mathrm{~nm}$; 2. $390-535 \mathrm{~nm}$; 3. 395-510nm e 4. 365$520 \mathrm{~nm}$ ); levou a um menor aumento de temperatura pulpar (1. 0,90 a $40 \mathrm{~s} ; 2$. $3,6^{\circ} \mathrm{C}$ a $40 \mathrm{~s} ; 3 \cdot 1,9^{\circ} \mathrm{C}$ a $10 \mathrm{~s}$ e $4 \cdot 6,4^{\circ} \mathrm{C}$ a $\left.10 \mathrm{~s}\right)$, necessitando de tempos comparáveis ao aparelho convencional. Os autores concluíram que o LED pode ser utilizado com sucesso na polimerização de restaurações dentais. 
MOORE; PLATT; DUKE ${ }^{44}$, em 2002, avaliaram o espectro de emissão de 3 aparelhos [CoolBlu (C), Dental Systems Int.; VersaLux (V), Centrix Inc.; FreeLight (FL), 3M/ESPE], a dureza de superfície e a profundidade de polimerização de nove resinas: Point4 (P4), Kerr; Tetric Ceram (TC), Ivoclar; Z250 (Z), 3M; Durafill (D), Kulzer; HelioMolar (HM), Ivoclar; Silux Plus (S), 3M; Flox-lt (F), JenericPentron; Renew (R), Bisco; Micronew (M), Bisco, em cores claras. A unidade halógena de quartzo Highlight (LH), ESPE foi usada como controle. Todas as lâmpadas foram operadas no modo padrão com 40s de exposição. Mediu-se o espectro de emissão com espectrômetro (S1000 Ocean Optics). Quatro medidas de dureza Knoop (200g) foram tomadas na superfície de topo e de base de três espécimes a $2 \mathrm{~mm}$ e definiu-se como adequada uma média base/topo $>0,8$. $\mathrm{O}$ teste Dunnett foi usado para comparar a dureza do controle com a das amostras polimerizadas com o LED. Observou-se que o espectro de emissão de luz para os aparelhos tipo LED era similar e consistia de um único pico centrado em torno de 460nm. Em contraste, o espectro da luz convencional estendeurse de 380 a 530nm com um pico bastante extenso entre $420-500 \mathrm{~nm}$. As resinas P4 e M, polimerizadas pelo LED, exibiram dureza de superfície significantemente mais baixa do que as polimerizadas com LH. Uma profundidade de polimerização de $2 \mathrm{~mm}$ foi encontrada com LH para todas as resinas exceto D, H, S e F. Encontrout se uma profundidade de polimerização de $2 \mathrm{~mm}$ para todos os aparelhos tipo LED na resina $Z$, para o LED FL na resina $R$ e com o LED $C$ na resina $M$. Concluituse que $2 \mathrm{~mm}$ de profundidade de polimerização não poderiam ser obtidos após ativação de 40s com LED em oito das resinas testadas. Isto também foi verdade 
para quatro das resinas polimerizadas por LH. Os dados sugeriram que pode ser necessário maior tempo de polimerização com o LED. 
3. PROPOSIÇÃo 


\section{3 - ProposiçÃo}

Este trabalho, fundamentado na Introdução e Revisão de Literatura, tem como objetivo avaliar comparativamente a resistência à tração da resina composta Z250 - 3M, nas cores A1 e A4, em função de diferentes fontes de luz e de tempos de ativação a fim de comprovar o desempenho da nova tecnologia LED para fotopolimerização da resina composta. 


\section{4 - Material e Método}

Para determinar a resistência à tração da resina composta em função do tipo fonte de luz, utilizou-se um aparelho de luz halógena Curing Light $2500^{12}$ (3M, lote 3017518 ) com intensidade de luz $670 \mathrm{~mW} / \mathrm{cm}^{2}$ (Figura $1 \mathrm{~A}$ ) e outro de diodo emissor de luz (LED) Ultraled-Dabi-Atlante ${ }^{74}$ (lote 4505H000/6 n.001112) com intensidade de luz $130 \mathrm{~mW} / \mathrm{cm}^{2}$ (Figura 1B). As especificações destes aparelhos encontram-se na Tabela 1. As intensidades de luz foram verificadas por um radiômetro comercial (Curing Radiometer Model 100 P/N - 10503/Demetron Research Corp.) imediatamente antes do uso dos aparelhos.

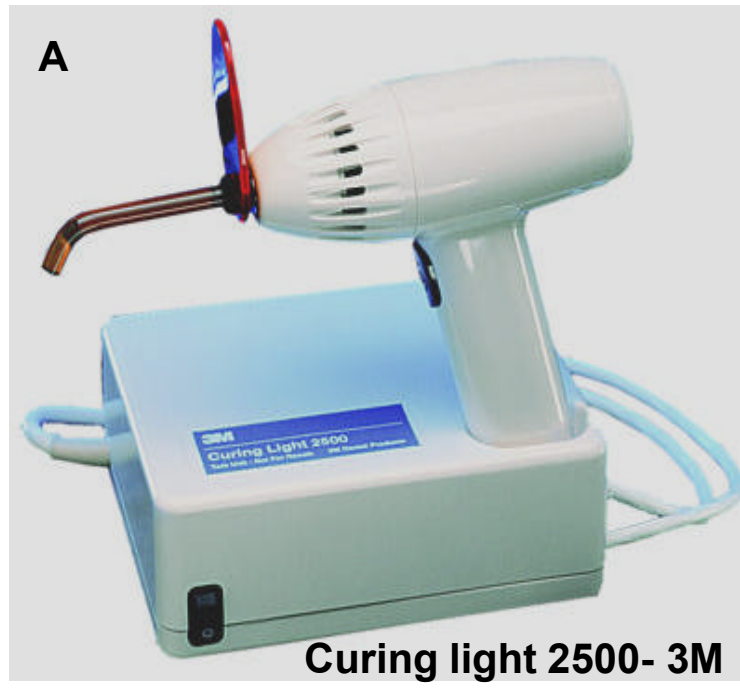

B

Figura 1 - Aparelhos fotopolimerizadores. 
Tabela 1 - Características dos aparelhos fotopolimerizadores usados.

\begin{tabular}{|c|c|c|c|c|c|c|}
\hline Produto & Marca & Tipo & $\begin{array}{c}\text { Diâmetro } \\
\text { Guia de } \\
\text { luz }\end{array}$ & $\begin{array}{l}\text { Freqüência } \\
\text { (Hz) }\end{array}$ & Potência & $\begin{array}{c}\text { Intensidade } \\
\text { de Luz } \\
\left(\mathrm{MW} / \mathrm{cm}^{2}\right)\end{array}$ \\
\hline $\begin{array}{l}\text { Curing } \\
\text { Light } \\
2500\end{array}$ & $3 \mathrm{M}$ & LH & $8 \mathrm{~mm}$ & $50 / 60$ & 75Watt & 670 \\
\hline Ultraled & $\begin{array}{c}\text { Dabi } \\
\text { Atlante }\end{array}$ & LED & $8 \mathrm{~mm}$ & $50 / 60$ & 4Watt & 130 \\
\hline
\end{tabular}

Utilizou-se a resina composta Z250 - 3M, definida pelo fabricante como um compósito polimerizável por luz e radiopaco, desenvolvida para restaurações de dentes anteriores e posteriores. A composição química, tempo de polimerização preconizado pelo fabricante e demais informações sobre o produto encontram-se na Tabela 2. As cores selecionadas foram A1 e A4 a fim de avaliar comparativamente se este fator poderia implicar em diferenças significantes nos valores de resistência à tração.

Tabela 2 - Características das Resinas compostas usadas.

\begin{tabular}{ccccccc}
\hline *Produto & Cor & No lote & Pol seg & Carga & $\begin{array}{c}\text { \% vol } \\
\text { Z }\end{array}$ & $\begin{array}{c}\text { Tamanho médio } \\
\text { partícula( } \boldsymbol{\mu m})\end{array}$ \\
\hline Z 250 & A1 & 1KP & 20s & Zirc/Síl & 60 & 0,19 a 3,3 \\
Z 250 & A4 & 2LE & 20s & Zirc/Síl & 60 & 0,19 a 3,3 \\
\hline *3M Dental Products & & & & & \\
\hline
\end{tabular}


Foram compostos oito grupos com 10 espécimes cada, sendo quatro grupos fotopolimerizados com luz halógena e quatro, com LED. Com o objetivo de avaliar a influência do tempo de polimerização na resistência à tração para ambos os aparelhos realizou-se o teste nos tempos de 20 s e 40 s para a cor A1 e 40 s e 80s para a cor A4. Na Tabela 3 encontra-se a distribuição dos espécimes nos diferentes grupos experimentais.

Tabela 3 Número de espécimes confeccionados para os diferentes grupos experimentais.

\begin{tabular}{ccccccc}
\hline $\begin{array}{c}\text { Resina } \\
\text { Z250/cor }\end{array}$ & \multicolumn{3}{c}{ LED } & \multicolumn{3}{c}{ LH } \\
\cline { 2 - 7 } & 20s & 40s & $\mathbf{8 0 s}$ & 20s & 40s & 80s \\
\hline A1 & 10 & 10 & - & 10 & 10 & - \\
A4 & - & 10 & 10 & - & 10 & 10 \\
\hline
\end{tabular}

Para confecção dos espécimes, utilizourse um conjunto de matrizes de aço inoxidável composto de duas partes semelhantes sendo que cada parte apresentava um orifício central cônico com 6,0mm de diâmetro menor e 8,0mm de diâmetro maior e 1,0mm de espessura (Figura 2A). As duas partes das matrizes foram posicionadas uma sobre a outra pela base menor do orifício central e adaptadas a um dispositivo metálico com dimensão exata para acomodar o conjunto de matrizes. Internamente a este dispositivo foi adaptada uma base de acrílico, juntamente com uma matriz de poliéster para evitar a aderência da resina (Figura 2B). A resina composta Z250 foi então inserida (Figura 2C) em incremento 
único, com auxílio de espátula (Thompson nº 4), adaptando, em seguida uma matriz de poliéster sobre a superfície da resina para regularizar a espessura do material e permitir o contato direto com a fonte de luz do aparelho fotopolimerizador. Realizou-se a polimerização conforme os tempos determinados para os diferentes grupos. Para permitir adequada polimerização dos dois segmentos do conjunto de matrizes a mesma foi realizada em duas etapas, então cada segmento recebeu metade do tempo estabelecido para cada espécime (Figura 2D). 
A

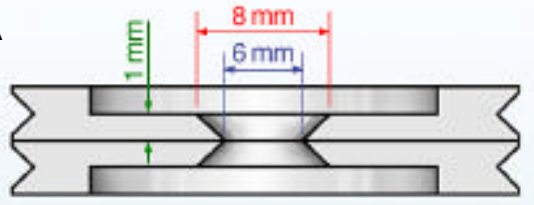

B
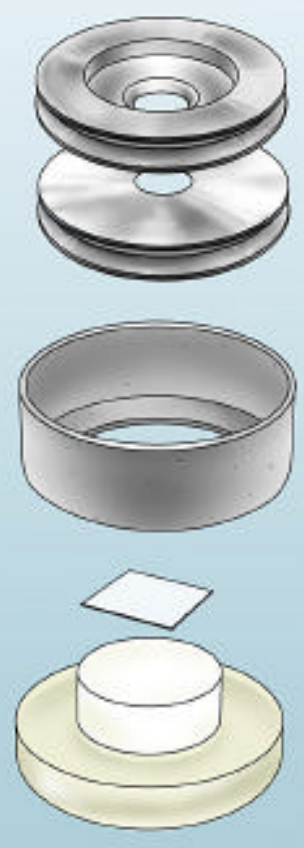

C

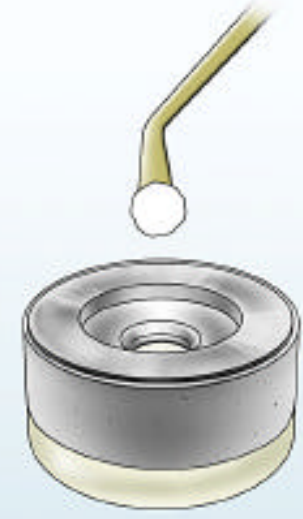

D
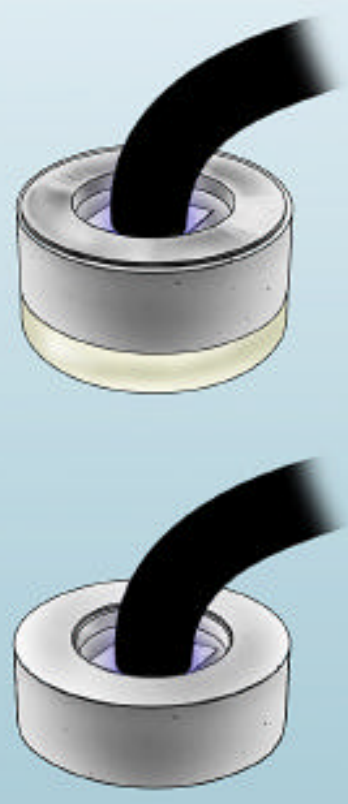

Figura 2 - A: Corte transversal do conjunto de matrizes posicionadas. B: Esquema do posicionamento das matrizes + dispositivo para acomodar 0 conjunto de matrizes + tira de poliéster + base de acrílico. C: Inserção da resina composta. D: Fotopolimerização em duas etapas; primeira etapa no segmento superior e segunda etapa, após remoção da base de acrílico e inversão do conjunto, no segmento inferior. 
Os espécimes de cada grupo foram numerados de um a dez, aguardandose o tempo de dez minutos após a polimerização, para que o conjunto matriz/espécime fosse levado à máquina de ensaios universal Kratos. Para possibilitar o teste de tração, este conjunto foi acoplado a um dispositivo de fixação do corpo de prova (Figura 3) e, em seguida conectado à carga ำ2 da máquina de ensaios (Figura 4A). O teste foi realizado (Figura 4B) a uma velocidade de $0,5 \mathrm{~mm} / \mathrm{min}$ até o momento da fratura do espécime, registrando o valor requerido para ruptura.

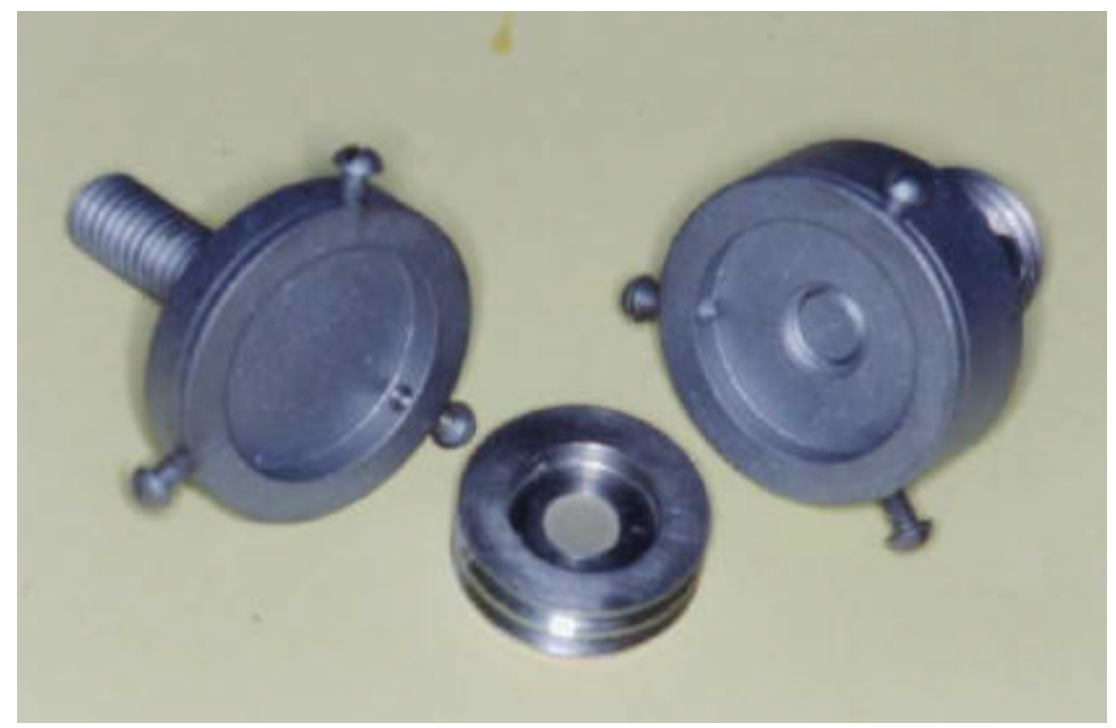

Figura 3 - Dispositivos para permitir o acoplamento dos corpos de prova na máquina de ensaios. 


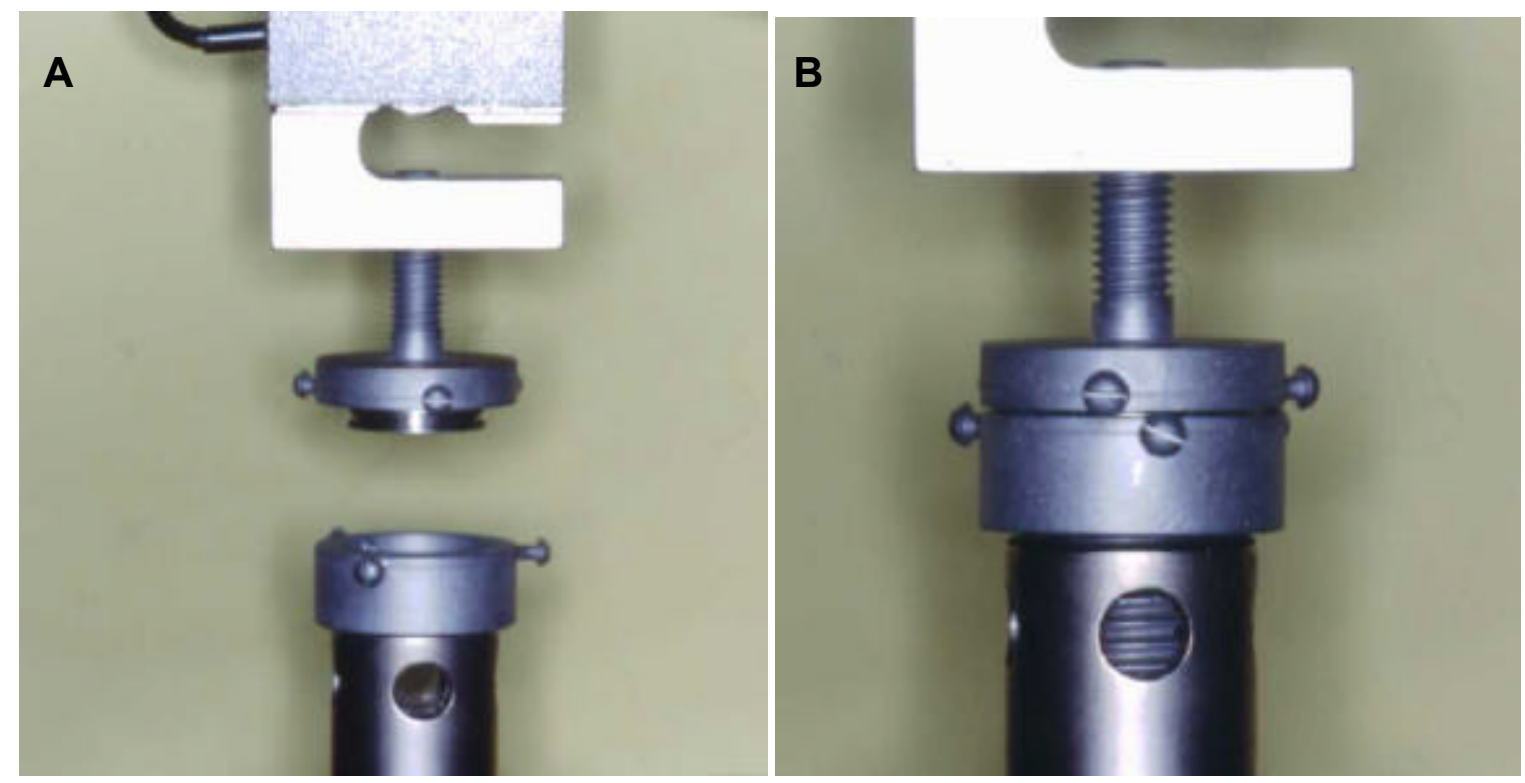

Figura 4 - A: Fixação da porção superior do corpo de prova junto à máquina de ensaio universal. B - Visualização completa do acoplamento do corpo de prova junto à referida máquina.

Os espécimes foram divididos em grupos conforme a Tabela 4 assim denominados: G1 - LH A1 20s; G2 - LH A1 40s; G3 - LH A4 40s; G4 - LH A4 80s; G5 - LED A1 20s; G6 - LED A1 40s; G7 - LED A4 40s e G8 - LED A4 80s. A tabela com os valores individuais de resistência à tração, dentro de cada grupo consta no Anexo1. 
Tabela 4 - Distribuição dos espécimes em grupos conforme fonte de luz, cor e tempo de ativação.

\begin{tabular}{c|c}
\hline GRUPOS & Fonte de luz + Cor + Tempo de ativação \\
\hline G1 & LH A1 20s \\
\hline G2 & LH A1 40s \\
\hline G3 & LH A4 40s \\
\hline G4 & LH A4 80s \\
\hline G5 & LED A1 20s \\
\hline G6 & LED A1 40s \\
\hline G7 & LED A4 40s \\
\hline G8 & LED A4 80s \\
\hline
\end{tabular}


5. Resultados 


\section{5 - Resultados}

Os valores de resistência à tração (em Kgf) obtidos para cada espécime de cada grupo encontram-se no Anexo 1. As médias obtidas e desvios padrão das condições avaliadas para a resina Filtek Z250 - 3M encontram-se na Tabela 5, para a cor A1 e na Tabela 6, para a cor A4, com respectiva representação gráfica na Figuras 5 e Figura 6. As médias obtidas foram submetidas à análise estatística de variância ANOVA a dois critérios, sendo estes fonte de luz e tempo de ativação. Considerourse diferença estatística não significante para $p>0,05 . A$ tabela com o estudo estatístico encontra-se no Anexo 2. No Anexo 3 encontra-se o gráfico da análise estatística para a cor A1 e no Anexo 4, o gráfico da análise estatística para a cor A4.

Tabela 5- Valores das médias e desvios padrão de resistência à tração em Kgf, para resina composta Filtek Z 250 - 3M na cor A1.

\begin{tabular}{cccc}
\hline AP & TEMPO & MÉDIAS & dp \\
\hline LH & 20 & 14,13 & 2,03 \\
LH & 40 & 13,85 & 2,46 \\
LED & 20 & 12,95 & 1,09 \\
LED & 40 & 13,46 & 2,02 \\
\hline
\end{tabular}


Figura 4 - Representação gráfica da Tabela 5.

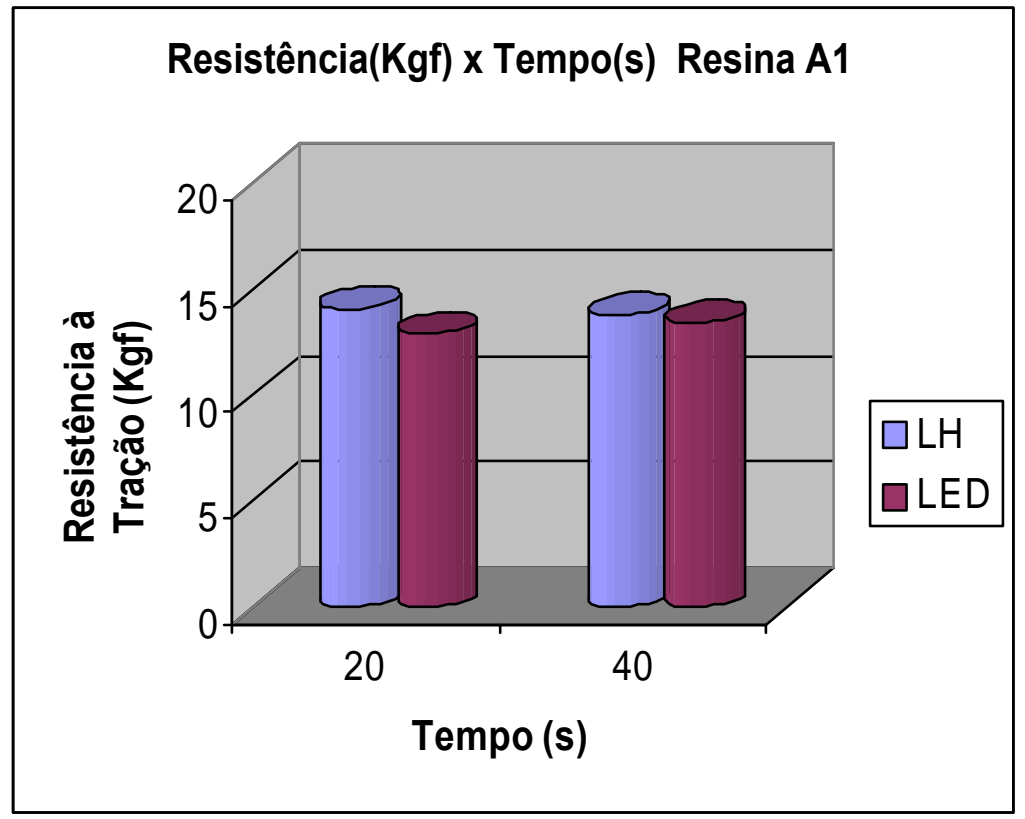

Tabela 6 - Valores das médias de resistência à tração em kgf e desvios padrão, para resina composta Filtek Z250 na cor A4.

\begin{tabular}{rccc}
\hline AP & TEMPO & MÉDIAS & Dp \\
\hline LH & 40 & 14,21 & 2,31 \\
LH & 80 & 14,42 & 1,97 \\
LED & 40 & 12,99 & 1,29 \\
LED & 80 & 14,25 & 2,89 \\
\hline
\end{tabular}


Figura 5 - Representação gráfica da tabela 6.

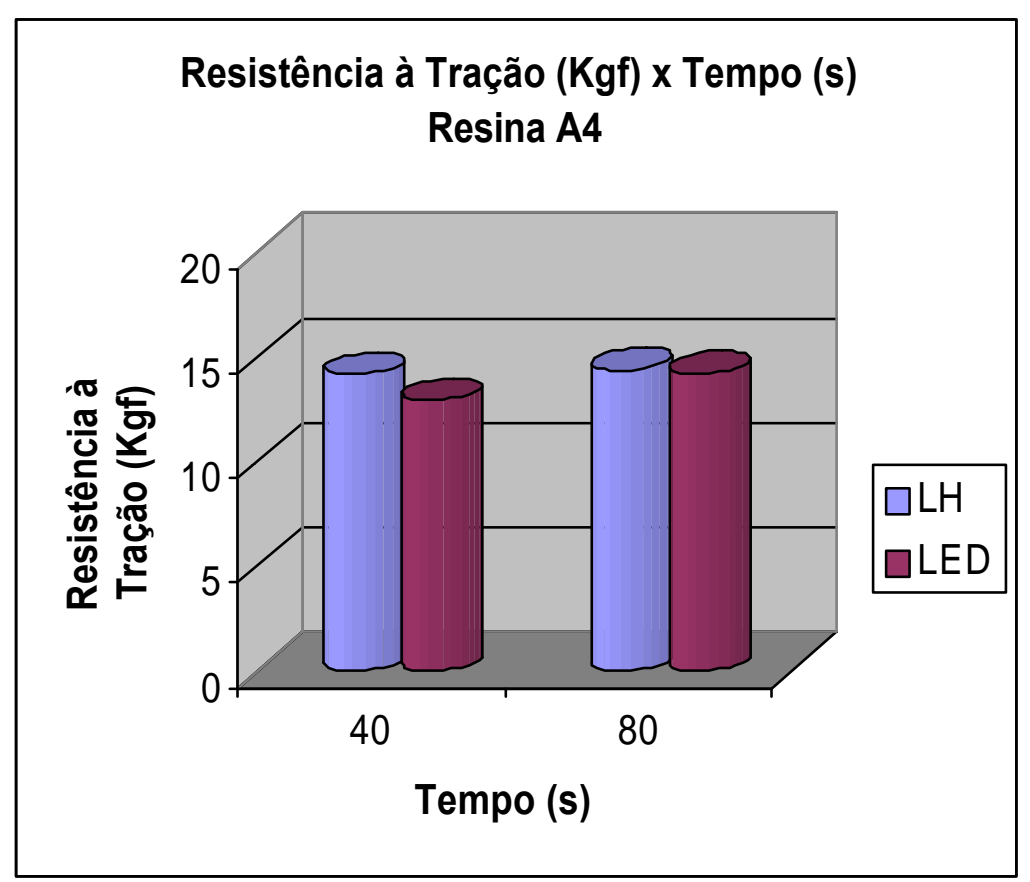

A análise estatística dos resultados para resina Filtek Z250 na cor A1 mostrou não haver diferenças estatísticas significantes nos valores de resistência à tração entre as variáveis (tempo de exposição e tipo de fonte de luz) para cor A1. Da mesma forma, para a cor A4 não houve diferenças estatísticas significantes nos valores de resistência à tração do material nas diferentes condições testadas. 
6. Discussão 


\section{6 - DISCUSSÃo}

\section{1-Sobre Metodologia}

A efetividade da polimerização da resina composta e o potencial de polimerização dos aparelhos fotopolimerizadores podem ser verificados direta ou indiretamente. Os métodos diretos de detecção do grau de conversão são estabelecidos por espectroscopia de infravermelho e espectroscopia de laser Raman, os quais determinam o quanto as ligações duplas de carbono são convertidas em ligações únicas. O método por laser possibilita a leitura da quantidade de grupos metacrilatos livres no material antes e após a exposição à luz. A espectroscopia por infravermelho, FTIR (Fourier Transform Infrared Spectrometer) monitora a alteração de absorbância das ligações duplas de carbono nos estados polimerizado e não polimerizado do material resinoso. $\mathrm{O}$ grau de conversão, independente do método utilizado, é o teste mais sensível, no entanto apresenta elevado custo, dificuldade técnica e o tempo de que demanda para execução impede sua utilização mais ampla 2,13,16,17,18,43,45,61.

Os métodos indiretos são os visuais e compreendem a metodologia por raspagem e testes de dureza ${ }^{27,61}$. No teste de raspagem, o material é fotopolimerizado por um determinado intervalo de tempo, removido da matriz e a porção não polimerizada, que se encontra amolecida, é raspada com um instrumento cortante manual até encontrar resistência similar à superfície voltada 
para a fonte de luz. A porção remanescente é medida, resultando no valor da profundidade de polimerização. Apesar de ser um teste simples, não indica a qualidade da polimerização ${ }^{80}$.

No teste de distinção óptica, por meio de estereomicroscopia detecta-se uma linha de diferente translucidez na superfície do espécime, a qual demarca a diferença entre material polimerizado e não polimerizado, fornecendo a profundidade de polimerização ${ }^{61}$. Apesar de ser de fácil execução, os valores de profundidade de polimerização são superestimados e o seu uso é limitado ${ }^{13}$.

O teste de dureza superficial tem sido um dos indicadores do grau de polimerização. Conforme YEARN; MACCLESFIELD ${ }^{80}$, a dureza é medida em intervalos de espaço ao longo do espécime polimerizado. O teste de dureza mede a resistência de um material à penetração de um dispositivo colocado sobre a superfície do mesmo por um determinado período de tempo, deixando uma impressão. Os testes de dureza mais usados em Odontologia são os de macrodureza Brinell e Rockwell e de microdureza Vickers e Knoop. Os testes de dureza Barcol e Shore são usados para materiais dentários, principalmente borrachas e plásticos. O teste de dureza para avaliação de profundidade de polimerização é o mais popular devido a sua simplicidade e é o mais utilizado para investigar os fatores envolvidos na profundidade de polimerização. Entretanto, a dureza superficial não indica a conversão na base do material, já que a dureza da superfície voltada para a luz tende a ser constante, mesmo com o uso de aparelhos de baixas intensidades ${ }^{20,26}$. 
Propriedades mecânicas dos materiais são igualmente dependentes do grau de conversão de polimerização, ou seja, da qualidade do polímero formado por determinada fonte de luz e servem para consubstanciar a aplicabilidade clínica de materiais e técnicas. Estas propriedades dos materiais, elásticas ou plásticas, são mensuradas sob força aplicada ou distribuição de tensões. A exemplo disto, a tensão estabelecida pelo teste de tração proporciona cargas axiais numa mesma direção, porém em sentidos divergentes, os quais tendem a distorcer ou alongar um corpo, resultando em deformação ou fratura por tração ${ }^{23}$. Os materiais odontológicos estão sujeitos à ação de cargas durante seu uso, principalmente durante a mastigação. Durante esta função, as altas forças e 0 estresse podem exacerbar defeitos inerentes ao material, resultando em inadequada resistência à fratura. Portanto, a resistência à tração constitui-se em propriedade válida para correlacionar possíveis alterações decorrentes da técnica de confecção de uma restauração ao comportamento intrínseco inerente ao material $^{7,23,30}$.

Com base nas considerações expostas acima, a metodologia eleita para o presente trabalho constitui-se de um teste de resistência à tração como forma de avaliar a consistência do polímero formado em função de diferentes fontes de luz e tempos de polimerização.

Consultando a literatura, no entanto, verifica-se que a maior dificuldade nos testes mecânicos é a produção de testes que representem adequadamente as dimensões das restaurações clínicas ${ }^{62}$. Muitos testes comumente empregam espécimes com dimensões clinicamente irreais, sendo que SHORTALL; 
UCTASLI; MARQUIS ${ }^{64}$ encontraram uma variação de volume de espécimes de 40 a $840 \mathrm{~mm}^{3}$. Para YEARN; MACCLESFIEL ${ }^{80}$ é essencial e necessário um método que realisticamente reproduza in vitro o que ocorrerá clinicamente.

Diante da necessidade de pesquisas laboratoriais que possam, da melhor forma aproximar-se da realidade clínica, foram confeccionados espécimes com espessura condizente com a técnica incremental preconizada por vários autores $^{6,57,60,65}$. Atendendo aos limites técnicos da técnica incremental, procura-se evitar os efeitos indesejáveis de segmentos com menor profundidade de polimerização, garantindo a maior conversão dos monômeros em todo o volume da resina composta. Da mesma forma, em se usando incrementos mínimos respeitam-se os aspectos da contração volumétrica inerente a este material. Espessuras de camadas incrementais não deverão exceder $2 \mathrm{~mm}$, tendo como ideal a espessura de $1 \mathrm{~mm}^{21,22,57}$.

Sabendo-se que, na espessura de $1 \mathrm{~mm}$ as variáveis tempo de exposição e intensidade de luz são fatores significantes ${ }^{6,57}$, a presente metodologia permitiu avaliar comparativamente a influência dos mesmos sobre os valores de resistência à tração da resina composta.

Quanto aos tempos de exposição praticados neste estudo, utilizou-se para a cor A1 o tempo de 20s, conforme indicado pelo fabricante, e de 40 s com o objetivo de se realizar uma análise comparativa entre os tempos e as fontes de luz utilizadas (LED e luz halógena). Para a cor A4, elevou-se o tempo indicado 
pelo fabricante para 40s e comparou-se com o tempo de 80 s a fim de avaliar uma possível influência da cor nos valores de resistência à tração.

A matriz metálica utilizada, que parece estar mais próxima da condição clínica $^{80}$, por possuir diâmetro junto à área de teste de $6 \mathrm{~mm}$, possibilitou que toda a extensão do orifício recebesse a transmissão de luz dos aparelhos fotopolimerizadores, uma vez que tanto a ponta do LED como do aparelho de LH apresentavam diâmetro de $8 \mathrm{~mm}$. Esta cobertura total do espécime é importante para promover uma polimerização uniforme em todo o seu diâmetro ${ }^{61}$.

Desta forma, foi possível avaliar a resistência à tração ou coesiva da resina composta utilizada, tendo como base dois segmentos de $1 \mathrm{~mm}$ que, polimerizados com as unidades fotopolimerizadoras do tipo LED e LH em diferentes tempos de ativação, permitiram observar a influência do grau de polimerização na resistência intrínseca do material.

\section{2- Sobre os resultados obtidos}

No diagrama adaptado de SHORTALL; HARRINGTON ${ }^{65}$ (Anexo 4) pode-se observar a banda de distribuição dos comprimentos de onda gerados pela luz visível e também a banda efetiva para a fotopolimerização dos materiais fotossensíveis, o que se faz necessário para melhor compreensão do desempenho dos aparelhos em discussão. A banda de luz visível, perceptível ao olho humano, possui uma extensão que abrange os comprimentos de onda de 
400 a 700nm. Dentro desta faixa de luz visível, a extensão de comprimentos de onda efetivos para a polimerização dos materiais restauradores fotoativados vai de 400 a $500 \mathrm{~nm}^{48}$. Os comprimentos de onda na região ultravioleta, abaixo de 400nm, pouco contribuem e devem, preferivelmente, ser eliminados. Aqueles acima de 500nm igualmente contribuem muito pouco para a polimerização, além de produzirem calor potencialmente deletério para a polpa e tecidos moles ${ }^{80}$.

Durante a polimerização, parte da luz que penetra no material sofre dispersão na interface matriz/partícula, além de ser absorvida por estes dois componentes. A luz penetra na superfície da restauração, mas sua absorção impede que adentre nas porções mais profundas. Desta forma a luz dilui-se ao passar através da resina, limitando a profundidade de polimerização, que é inversamente proporcional à dispersão de luz. Deste modo, o grau de polimerização da resina composta depende de sua composição e da interação entre os fatores que dificultam ou facilitam a transmissão da luz, tais como: propriedades ópticas da mistura resina/partícula, tamanho e quantidade de partículas $2,51,71,80$, concentração do fotoiniciador e espessura de material. No entanto, para qualquer formulação de material, as características de cura são governadas principalmente pela efetividade da fonte de irradiação, considerando a intensidade de luz emitida, a distribuição da mesma no espectro de luz visível, o alinhamento da fonte ativadora e tempos de ativação ${ }^{13,27,34,48}$.

Desde o final da década de 70, o aparelho de luz halógena (LH) é o mais usado na polimerização de materiais fotossensíveis por profissionais da área odontológica. Este aparelho possui uma lâmpada de luz halógena de quartzo- 
tungstênio, que ao ser acionado por uma corrente elétrica, ativa um filamento de tungstênio extremamente fino, funcionando como um resistor e, quando fortemente aquecido, emite uma radiação eletromagnética em forma de luz visível $^{20}$.

As lâmpadas variam de 35 a 150W, o que não pode ser usado para comparar a eficiência dos mesmos. A energia luminosa emitida varia numa extensão de 300 a 1000nm e inclui energia na banda do infravermelho e ultravioleta, portanto a extensão de comprimentos de onda emitidos é tão vasta quanto a da luz branca, sendo muitos destes desnecessários ao processo de fotopolimerização ${ }^{67}$. Por isso, os fabricantes colocam um filtro entre a lâmpada e o guia de luz, para limitar a energia radiante emitida à extensão necessária à polimerização, ou seja, dentro da banda de absorção da $C Q^{48}$. O filtro também possui a finalidade de eliminar calor desnecessário e incandescência da energia em excesso, não utilizada para fotopolimerização. Com a colocação do filtro, $10 \%$ da intensidade de luz gerada diminui.

Ao abordar-se o aspecto tipo de irradiação emitida pelos aparelhos empregados neste estudo, fica claro o grande trunfo da nova tecnologia LED. Ao contrário dos aparelhos de $\mathrm{LH}$, que como relatado anteriormente, emitem luz numa extensa faixa do espectro visível, o LED emite luz azul numa banda estreita do espectro de luz visível, o qual convenientemente coincide com o espectro de ativação da CQ. De acordo com $\mathrm{NOMOTO}^{48}$ o mais adequado comprimento de onda para a polimerização dos materiais fotossensíveis que contêm $\mathrm{CQ}$ como fotoativador, está na faixa do espectro de 450 - 490nm, sendo que o mais 
eficiente é o de $470 \mathrm{~nm}$. A literatura mostra que é nesta banda do espectro de luz visível que o LED concentra a maior intensidade de energia emitida, com um pico de emissão por volta de $470 \mathrm{~nm}$, o ideal para o fotoativador $\mathrm{CQ}^{49,30,48}$. Portanto, são aparelhos que não necessitam de filtros, uma vez que comprimentos de onda inespecíficos, não importantes para a fotopolimerização, não são gerados. A exemplo disto, a energia na faixa de $500 \mathrm{~nm}$, geradora de calor, não é emitida, levando a um mínimo aquecimento, dispensando a instalação de ventilador inclusive. No trabalho de FRANCO; NAVARRO ${ }^{21}$, avaliou-se a liberação de calor durante 0 procedimento de polimerização, e verificou-se sua ocorrência substancialmente inferior para o sistema LED $\left(3^{\circ} \mathrm{C}\right)$ em relação aos aparelhos de luz halógena ( 10 a $\left.16^{\circ} \mathrm{C}\right)$.

As lâmpadas de LH, originalmente desenvolvidas para iluminar ambientes ou luzes de faróis de automóveis aquecem, pois são incandescentes; vão ao rubro pela geração de calor, de maneira que a lâmpada torna-se extremamente quente. A temperatura perto do bulbo alcança aproximadamente $400^{\circ} \mathrm{C}$. A energia perdida em função da geração de calor chega a $70 \%$ e, conseqüentemente somente $10 \%$ da energia elétrica são usados para emissão de luz visíve ${ }^{25}$. Devido às altas temperaturas geradas pelo aquecimento do bulbo faz-se necessária a colocação de um ventilador para resfriá-lo, o que aumenta o consumo de energia e a complexidade do aparelho ${ }^{51}$. A presença do calor durante o funcionamento leva a variações da condição física da lâmpada (bulbo), diminuindo com o tempo de uso, a intensidade de luz emitida e o potencial de polimerização do aparelho. Estas variações são: congelamento e escurecimento 
do bulbo, degradação do bulbo, deterioração óptica do filtro com manchamento e trincas e degradação do refletor da lâmpada. É importante entender que estas mudanças, as quais ocorrem principalmente na lâmpada, acontecem de forma gradativa antes da mesma queimar e o que é mais grave, sem que o profissional se aperceba disto ${ }^{47,78,17,20}$. A proporção final de extensão do comprimento de onda disponível para polimerização de resina composta é de somente $1 \%$ da energia total inicial da lâmpada ${ }^{24}$. A intensidade de luz ideal, requerida para os aparelhos de $\mathrm{LH}$, é de $400 \mathrm{~mW} / \mathrm{cm}^{2}$, visto que muito da energia emitida é convertida em calor e em luz de comprimentos de onda supérfluos, portanto apenas uma porcentagem da energia luminosa emitida será realmente aproveitada para fotopolimerização $0^{51}$.

Diferentemente aos aparelhos de $\mathrm{LH}$, a relativa simplicidade que envolve a emissão de luz pela tecnologia LED (diodo emissor de luz) direcionou estes dispositivos para o uso odontológico. Apresentando ainda como uma segunda grande vantagem sobre os aparelhos de LH, a vida útil extremamente longa de 10000 horas $^{24,30,39,40,41}$ ou segundo FUJIBAYASHI et al. ${ }^{24}$ podendo chegar a várias vezes este valor. Se utilizado com o regime tensão/intensidade otimizado, ocorrerá pequena degradação da luz com o passar do tempo. Estes são aparelhos altamente resistentes aos atos de ligar e desligar durante o uso dos mesmos. Com menor número de componentes, podem ser montados de forma portátil e podem funcionar com baterias.

Para os aparelhos de LH a qualidade de luz emitida é determinada pela idade do bulbo, que normalmente não deveria exceder seis meses; pela 
integridade do refletor de luz do bulbo, que deverá estar livre de manchamentos e opacidade e pela adequada filtração da luz ${ }^{46}$. O tempo de vida útil de uma LH é muito curto, estima-se que sua durabilidade é de somente 50 horas, em média 38,6 horas. Ainda, se a lâmpada é freqüentemente ligada e desligada, o tempo de vida do bulbo encurta ${ }^{25}$. Desta forma para os aparelhos de luz halógena, a intensidade de luz é inversamente proporcional à idade da unidade. ARAÚJO; ARAÚJO; FERNANDES ${ }^{1}$ observaram, ao medir a intensidade de luz de 45 aparelhos com mais de cinco anos, considerados antigos, que apenas $11,1 \%$ apresentavam intensidade adequada.

Com base no exposto acima, fica evidente que a qualidade dos trabalhos executados com os aparelhos de luz halógena é fortemente dependente do seu bom funcionamento e manutenção. Um monitoramento periódico da intensidade de luz emitida se faz necessário, assim como a substituição das lâmpadas e filtros deve ser feita em uma freqüência que a maioria dos profissionais desconhece. Para estes aparelhos, variações de voltagem da corrente elétrica que entra no equipamento também podem alterar a intensidade emitida ${ }^{16,34,38,80}$. Inclusive, detritos aderentes na ponta da fonte de luz, a repetida esterilização, e danos que a mesma possa apresentar prejudicam a correta emissão de luz ${ }^{34}$.

Apesar dos aparelhos de LH servirem a classe odontológica a mais de vinte anos, a literatura mostra que muitos autores já apontavam as particularidades relatadas acima como inconvenientes inerentes a este tipo de equipamento $^{3,5,25,41,67}$. Principalmente porque 0 bom funcionamento destes equipamentos depende do zelo do profissional com a manutenção regular. 
BARGHI; BERRY; HATTON ${ }^{3}$ observaram que muitos aparelhos que emitem luz halógena não alcançam a mínima intensidade de luz especificada pelos fabricantes, devido à falta de manutenção e a não checagem da intensidade de luz do mesmo, ou ainda pela não substituição regular do filtro e/ou lâmpada.

O mecanismo pelo qual a luz é gerada nos aparelhos LED é mais simples. O LED é uma combinação de semicondutores, que emitem luz azul por mecanismo de eletroluminescência. Constitui-se de uma junção do tipo n-p, isto é, apresenta de um lado um semicondutor do tipo n, doador de elétrons e de outro, um semicondutor do tipo p, rico em espaços receptores de elétrons. Quando a tensão gerada é capaz de vencer a barreira de energia do intervalo denominado GAP, ocorre a passagem dos elétrons da camada de valência para a camada de condução, gerando fluxo de elétrons e espaços. Na junção n-p ocorre o decaimento de elétrons, pela recombinação do par elétron-espaço, ocorrendo a emissão de fótons. O espectro de emissão do LED relaciona-se diretamente ao material que compõem o semicondutor. $\mathrm{O}$ baixo consumo de corrente elétrica deve-se a própria característica da curva tensão versus intensidade de corrente inerente aos semicondutores. Estes apresentam potência individual de 5 a $10 \mathrm{~mW}$ e, por isso, são montados com arranjo de vários LEDs azuis para o uso odontológico ${ }^{39,46}$.

Empregaram-se os LEDs, primeiramente usados como marcadores de velocidade, com potência de $1,2 \mathrm{~mW}$, em experimentos para a polimerização de uma resina composta sugerindo boas perspectivas para a montagem de um dispositivo de mão com maior potência ${ }^{40}$. A literatura reconhece que; NAKAMURA 
et al. ${ }^{46}$, ao colocarem uma fina camada de InGaN modificando a estrutura do LED, produziram $5,6 \mathrm{~mW}$ a $20 \mathrm{~mA}$, emitindo luz azul numa extensão do espectro com um pico definido a 405nm, deram início à geração dos LEDs com alta potência de luz azul em um estreito espectro de emissão.

Vários trabalhos que descrevem o êxito do LED na polimerização da resina composta justificam-no pela estreita extensão de distribuição de comprimento de onda emitido, com pico bem definido perto de $470 \mathrm{~nm}$, o ideal para excitar a $\mathrm{CQ}^{24,30,40,41}$. Isto sugere que a luz irradiada pelo LED azul é mais efetiva na polimerização de resinas compostas ${ }^{30,31,39}$. Assim como várias pesquisas publicadas pela comunidade científica, a presente pesquisa confirma o potencial da tecnologia LED na polimerização da resina composta $^{5,18,24,25,29,31,32,35,39,40,50,54,67,77,78}$. A literatura demonstra que, dentre os fatores referentes à resina composta que modificam o processo de polimerização, tais como composição, variação de cor e espessura do material, este último é o de maior influência ${ }^{7,27,56,38,60,62}$. É bastante evidente que o problema da profundidade de polimerização ocorre independentemente da fonte de luz utilizada, já que a intensidade de luz é reduzida drasticamente com o aumento de espessura do material| ${ }^{25,57,77,78}$. A técnica da inserção incremental da resina composta tem sido indicada com o propósito de reduzir a contração de polimerização, bem como garantir a completa conversão dos monômeros em todo o volume da resina composta, sendo que a espessura máxima de resina deve ser de $2 \mathrm{~mm} .^{6,57}$.Na avaliação aqui realizada, a observância da espessura mínima 
preconizada pela literatura foi fator coadjuvante das adequadas médias de resistência à tração conseguidas.

Quanto ao fator cor, as médias obtidas de resistência à tração não denotaram diferenças significativas, o que está de acordo com HARRINGTON; WILSON; SHORTALL ${ }^{27}$, PFEIFER et al. $^{54}$ e SHORTALL; HARRINGTON,63 que respectivamente avaliaram; tempo de irradiação, microdureza de superfície e da base e dureza Vickers com resinas de cores clara e escura de mesma composição e não observaram uma influência do fator cor nos resultados obtidos.

FOWLER et al. $^{20}$, recomendam o tempo de exposição à luz de 60 s com o propósito de compensar a queda nos valores de intensidade de luz, assim como RUEGGEBERG et al. $^{57}$ da mesma forma, indicaram para aparelhos fotopolimerizadores que apresentam baixa intensidade de luz. Os resultados observados neste estudo evidenciam que, para a espessura de $1 \mathrm{~mm}$, o tempo de 20s recomendado pelo fabricante para a $\mathrm{LH}$ foi efetivo, assim como para o aparelho LED.

No entanto, a semelhança dos valores de resistência à tração obtidos entre LED e LH neste trabalho parece estar de acordo com a literatura apresentada ao longo dos últimos anos sobre esta nova tecnologia ${ }^{5,24,25,29,30,31,40,48}$. A emissão de energia numa faixa de extensão bastante estreita e em maior proporção coincidente com o pico de absorção da $\mathrm{CQ}$ faz com que o fluxo de energia liberado para a resina seja quase totalmente aproveitado. Apesar dos valores de intensidade de saída registrados pelo radiômetro serem, muitas vezes, bastante 
inferiores aos de um aparelho de LH a polimerização ocorre com a mesma efetividade conforme os trabalhos observados na literatura e os resultados obtidos nesta pesquisa.

Sucessivos trabalhos ${ }^{5,10,30,31,41}$ demonstram que a relação da qualidade de luz emitida (em nm) parece ter grande importância no potencial de polimerização dos aparelhos. FUJIBAYASHI et al. ${ }^{24}$ compararam a profundidade de polimerização de dois aparelhos tipo LED (L1 e L2) e um aparelho de LH. Os aparelhos de diodo emissor de luz eram formados por 61 LEDs cada, com emissão de comprimentos de onda distintos ( $L 1=450 \mathrm{~nm}$ e L2 $=470 \mathrm{~nm}$ ), ambos calibrados para a intensidade de $100 \mathrm{~mW} / \mathrm{cm}^{2}$. O L2 apresentou os maiores valores de profundidade de polimerização, justificados, segundo os autores, pela distribuição da energia emitida no espectro de luz quase totalmente na banda entre 430 e 550nm, com pico bem definido e superior aos demais aparelhos ( $\mathrm{L} 1=$ 444nm; L2 = 466nm; LH = 484nm). Portanto, a energia luminosa emitida foi marcadamente melhor aproveitada pelo aparelho L2 (L1- 84\%; L2=96\%; LH= $94 \%)$.

De grande importância também, foi o estudo de MILLS; JANDT; ASHWORTH ${ }^{41}$, em que se obtiveram maiores valores de profundidade de polimerização com um conjunto de 25 LEDs, o qual emitia menor intensidade de luz do que o aparelho de LH. A real intensidade emitida dentro da faixa de sensibilização dos materiais fotoativados $(410$ - 500nm) verificada por meio de fluxo espectral, foi de $276 \mathrm{~mW} / \mathrm{cm}^{2}$ para o LED e $388 \mathrm{~mW} / \mathrm{cm}^{2}$ para a $\mathrm{LH}$. No entanto $95 \%$ da intensidade de luz total emitida pelo LED foi efetivamente 
aproveitada, pois convenientemente coincidia com o pico de maior absorção para a CQ.

JANDT et al. ${ }^{30}$ também verificaram valores bastante similares de profundidade de polimerização e de resistência à compressão entre o LED e LH, a despeito da significativa diferença em intensidade de luz $\left(350 \mathrm{~mW} / \mathrm{cm}^{2}\right.$ e $755 \mathrm{~mW} / \mathrm{cm}^{2}$ respectivamente). O LED, com um pico máximo de emissão em $465 \mathrm{~nm}$, apresentou um total de energia emitida duas vezes maior do que o aparelho de LH na faixa de 450 a 470nm, o que justifica a sua efetiva performance.

De maneira semelhante a este trabalho MEDEIROS ${ }^{39}$ obteve, na espessura mínima de $0,7 \mathrm{~mm}$ e polimerização por LED, valores de microdureza Vickers estatisticamente semelhantes aos conseguidos com polimerização por LH durante 40s (tempo preconizado pelo fabricante) e com o laser de argônio por 10s, na superfície oposta à luz. Parece claro que, em experimentos onde um conjunto de sete LEDs é usado, respeitando-se o uso de incrementos mínimos de resina composta, a qualidade do polímero formado é assegurada. A maioria dos trabalhos publicada comprova o potencial de polimerização do LED em profundidade de polimerização, testes de resistência à compressão e dureza de superfície ${ }^{5,17,21,25,30,33,35}$. Os resultados insatisfatórios relatados, no entanto, advêm de pesquisas em que as espessuras de resina ultrapassam os valores clinicamente recomendados e que, portanto, não podem contra-indicar a utilização do LED para fotopolimerização em Odontologia ${ }^{25,44,55}$. Por outro lado, percebe-se que trabalhos em o LED foi efetivo na polimerização em espessuras 
de $2 \mathrm{~mm}$, a unidade envolvia um conjunto com maior número de $\operatorname{LEDs}^{16,48,52,71}$, o que aumenta a intensidade de luz emitida e a conseqüente maior profundidade da transmissão luminosa. Valores de dureza de superfície inferiores aos comparados com LH foram observados por KURACHI et al. ${ }^{33}$, porém com um dispositivo de apenas 6 LEDs que emitiu um total de irradiação de $79 \mathrm{~mW} / \mathrm{cm}^{2}$.

RUEGGEBERG ${ }^{56}$ e SUH $^{68}$ estabeleceram o conceito de energia total de polimerização necessária para efetivar a ativação das resinas compostas, por meio do resultado do produto da intensidade de luz com o tempo de ativação. Não obstante esta conceituação, a presente pesquisa não sinalizou para uma relação direta entre a intensidade de luz e tempo de polimerização, uma vez que os grupos polimerizados com o aparelho LED, com intensidade de luz significativamente menor $\left(130 \mathrm{~mW} / \mathrm{cm}^{2}\right)$ que o aparelho de $\mathrm{LH}\left(670 \mathrm{~mW} / \mathrm{cm}^{2}\right)$, mostraram valores similares de resistência à tração. Esta observação também é referenciada por JANDT et al. $^{30}$, que observaram resultados numéricos semelhantes com o LED, apesar de sua intensidade de luz 2,2 vezes menor em relação ao aparelho de LH. Diante disso, os autores observaram que a proporção de polimerização aumenta apenas 1,44 vez, quando a intensidade é dobrada. Deve-se lembrar que esta relação é válida quando se utilizam dois aparelhos de diferentes intensidades de luz, mas com os demais parâmetros: tempo de ativação, material, diâmetro da ponta ativa do aparelho e espectro de luz emitida mantidos constantes. Já que o espectro de luz emitido entre os aparelhos do tipo LED e LH é notadamente distinto, uma comparação apenas entre intensidade de luz não parece ser correta. Desta forma, salienta-se a necessidade de estudos 
que permitam avaliar de forma equivalente estes parâmetros, ressaltando-se que a avaliação das propriedades mecânicas de materiais polimerizados com LED e LH é mais útil no presente momento.

Ainda sobre os novos conceitos de polimerização abordados anteriormente, percebe-se que as resinas compostas mais recentes podem empregar diferentes fotoiniciadores, fazendo com que o espectro de emissão da unidade fotopolimerizadora seja um importante fator para as propriedades finais da restauração ${ }^{57,68}$. A energia necessária a cada compósito deverá ser incluída no rótulo do produto, assim como os aparelhos de fotopolimerização deverão ter, rotulados, a sua intensidade de luz emitida e o comprimento de onda correspondente. Esta informação torna-se mais necessária ainda para o uso dos aparelhos LED, que comprovadamente polimerizam materiais fotossensíveis quando o fotoiniciador é a CQ, a qual necessita de concentração de energia próxima a seu maior pico de absorção (468nm). O advento de novos fotoiniciadores, como o fenil-propanodiona (PPD), tem revelado um componente distinto na polimerização de algumas resinas compostas por requererem energia na faixa de $410 \mathrm{~nm}^{51}$. Neste sentido, aparelhos que não emitirem energia com esta característica não efetivarão a fotopolimerização. Face ao exposto, o aparelho do tipo LED, similar ao utilizado na presente pesquisa, não seria efetivo na polimerização de resinas com componentes iniciadores fora do espectro de luz emitido pela unidade fotopolimerizadora.

Embora JANA; SANTOS; CORRÊA ${ }^{29}$ tenham verificado que o LED não foi efetivo na polimerização da resina Definite, justificando que a mesma contém 
fotoiniciadores sensíveis apenas à energia próxima ao espectro ultravioleta; FRANCO; NAVARRO ${ }^{21}$ observaram a efetividade dos aparelhos de LH e LED na polimerização de várias resinas compostas disponíveis no mercado odontológico, inclusive o compósito Definite, quando da avaliação da profundidade de polimerização.

Sendo a especificidade do espectro de emissão de energia de um aparelho LED, determinado pelo material que reveste os semicondutores ${ }^{39}$, a possibilidade de implementação de novos aparelhos para polimerização de resinas compostas ou materiais fotoativados que contenham outros fotoiniciadores, que não a $C Q$, parece ser bem viável.

Em que pese a necessidade de continuidade dos trabalhos para aprimoramento dos aparelhos LED, as evidências corroboram com a afirmação de $\mathrm{NOMOTO}^{46}$ de que a intensidade de luz no comprimento de onda de $470 \mathrm{~nm}$ pode ser o guia na eficiência da polimerização. Desta forma, a tecnologia LED tem se direcionado para este fim e se mostra cada vez mais eficaz na fotopolimerização das resinas compostas. 
7. Conclusão 


\section{7 - CONCLUSÃO}

Após a análise estatística dos resultados obtidos, pode-se concluir que:

1 - O aparelho fotopolimerizador LED foi tão efetivo na polimerização da resina composta quanto o aparelho de luz halógena.

2 - O aumento do tempo de polimerização não exerceu influência na resistência à tração da resina composta, independente do tipo de aparelho fotopolimerizador e da cor do material.

3 - A resistência à tração para a resina $Z 250$ nas cores A1 e A4 não foi afetada pela variação do tempo de polimerização nem pelas fontes de luz halógena e LED. 


\section{ANEXO I}

Tabela de Resultados das medições obtidos por espécime

Grupo 1 - LH - Resina A1 - 20 segundos

\begin{tabular}{|c|c|c|c|}
\hline $\begin{array}{c}\text { Resina Z250 3M } \\
\text { COR }\end{array}$ & $\begin{array}{c}\text { APARELHO } \\
\text { FOTOPOLIMERIZADOR }\end{array}$ & $\begin{array}{c}\text { TEMPO } \\
\text { (s) }\end{array}$ & $\begin{array}{c}\text { RESISTÉNCIA À } \\
\text { TRAÇÃO (kgf) }\end{array}$ \\
\hline \multirow[t]{10}{*}{ 年 } & \multirow[t]{10}{*}{ (6) } & \multirow{10}{*}{20} & 16,90 \\
\hline & & & 11,68 \\
\hline & & & 15,95 \\
\hline & & & 14,03 \\
\hline & & & 14,32 \\
\hline & & & 12,15 \\
\hline & & & 16,45 \\
\hline & & & 14,88 \\
\hline & & & 14,03 \\
\hline & & & 10,95 \\
\hline \multicolumn{4}{|c|}{ Grupo 2 - LH - Resina A1 - 40 segundos } \\
\hline \multirow{10}{*}{ A1 } & \multirow{10}{*}{ LH } & \multirow{10}{*}{40} & 11,18 \\
\hline & & & 15,68 \\
\hline & & & 18,63 \\
\hline & & & 13,55 \\
\hline & & & 12,85 \\
\hline & & & 16,90 \\
\hline & & & 12,40 \\
\hline & & & 11,57 \\
\hline & & & 11,98 \\
\hline & & & 13,73 \\
\hline
\end{tabular}

Grupo 3 - HL - Resina A4 - 40 segundos

\begin{tabular}{|c|c|c|c|}
\hline \multirow{10}{*}{ A4 } & \multirow{10}{*}{ LH } & \multirow{10}{*}{40} & 17,33 \\
\hline & & & 14,60 \\
\hline & & & 10,80 \\
\hline & & & 14,18 \\
\hline & & & 13,88 \\
\hline & & & 13,80 \\
\hline & & & 12,43 \\
\hline & & & 17,33 \\
\hline & & & 16,45 \\
\hline & & & 11,30 \\
\hline
\end{tabular}

Grupo 4- HL - Resina A4 - 80 segundos

\begin{tabular}{|c|c|c|c|}
\hline \multirow{10}{*}{ A4 } & \multirow{10}{*}{ LH } & \multirow{10}{*}{80} & 17,70 \\
\hline & & & 11,50 \\
\hline & & & 12,45 \\
\hline & & & 12.78 \\
\hline & & & 15,25 \\
\hline & & & 15,57 \\
\hline & & & 16,33 \\
\hline & & & 14,88 \\
\hline & & & 15,07 \\
\hline & & & 12,75 \\
\hline \multicolumn{4}{|c|}{ Grupo 5 - LED - Resina A1 - 20 segundos } \\
\hline \multirow{10}{*}{ A1 } & \multirow{10}{*}{ LED } & \multirow{10}{*}{20} & 14,65 \\
\hline & & & 13,53 \\
\hline & & & 13,88 \\
\hline & & & 11,38 \\
\hline & & & 13,98 \\
\hline & & & 12,15 \\
\hline & & & 11,80 \\
\hline & & & 13,57 \\
\hline & & & 12,18 \\
\hline & & & 12,43 \\
\hline
\end{tabular}


Grupo 6 - LED - Resina A1 - 40 segundos

\begin{tabular}{|c|c|c|c|}
\hline \multirow{10}{*}{ A1 } & \multirow{10}{*}{ LED } & \multirow{10}{*}{40} & 11,63 \\
\hline & & & 12,57 \\
\hline & & & 15,00 \\
\hline & & & 10,85 \\
\hline & & & 13,30 \\
\hline & & & 15,15 \\
\hline & & & 12,00 \\
\hline & & & 17,45 \\
\hline & & & 14,48 \\
\hline & & & 12,23 \\
\hline \multicolumn{4}{|c|}{ Grupo 7 - LED - Resina A4-40 segundos } \\
\hline \multirow{10}{*}{ A4 } & \multirow{10}{*}{ LED } & \multirow{10}{*}{40} & 11,10 \\
\hline & & & 13,15 \\
\hline & & & 14,00 \\
\hline & & & 12,70 \\
\hline & & & 11,88 \\
\hline & & & 13,03 \\
\hline & & & 11,28 \\
\hline & & & 14,35 \\
\hline & & & 15,00 \\
\hline & & & 13,45 \\
\hline \multicolumn{4}{|c|}{ Grupo 8 - LED - Resina A4 - 80 segundos } \\
\hline \multirow{10}{*}{ A4 } & \multirow{10}{*}{ LED } & \multirow{10}{*}{80} & 15,63 \\
\hline & & & 14,82 \\
\hline & & & 20,95 \\
\hline & & & 16,00 \\
\hline & & & 12,35 \\
\hline & & & 12,93 \\
\hline & & & 13,48 \\
\hline & & & 14,05 \\
\hline & & & 11,35 \\
\hline & & & 11,03 \\
\hline
\end{tabular}




\section{ANEXO II}

Tabela de Resultados Estatísticos

Resina Cor A1 - Valores de Média e Desvio Padrão

\begin{tabular}{|c|c|c|c|}
\hline APARELHO & TEMPO (s) & $\begin{array}{c}\text { MÉDIA DA RESISTÉNCIA Ȧ } \\
\text { TRAÇÃO (Kgf) }\end{array}$ & $\begin{array}{c}\text { DESVIO PADRÃO DA } \\
\text { RESISTÊNCIA À TRAÇÃO } \\
\text { (Kgf) }\end{array}$ \\
\hline LH & 20 & 14,13 & 2,03 \\
\hline LH & 40 & 13,85 & 2,46 \\
\hline LED & 20 & 13,00 & 1,00 \\
\hline LED & 40 & 13,46 & 2,02 \\
\hline
\end{tabular}

COR A1

ANOVA a dois critérios.

Resina Cor A1 - Análise de Variância a 2 critérios:

\begin{tabular}{|c|c|c|c|c|c|c|}
\hline Efeito & gl efeito & qm efeito & gl erro & qm erro & $\mathrm{F}$ & $\mathrm{P}=$ \\
\hline Aparelho & 1 & 6,084000 & 36 & 3,866398 & 1,573557 & 0,217775 \\
\hline Tempo (s) & 1 & 0,125440 & 36 & 3,866398 & 0,032444 & 0,858068 \\
\hline Interação & 1 & 1,592010 & 36 & 3,866398 & 0,411755 & 0,525145 \\
\hline
\end{tabular}

$\mathrm{Ns}=$ diferença estatisticamente não significante $(p>0,05)$

B - Resina Cor A4 - Valores de Média e Desvio Padrão

\begin{tabular}{|c|c|c|c|}
\hline APARELHO & TEMPO (s) & $\begin{array}{c}\text { MÉDIA DA RESISTÉNCIA À } \\
\text { TRAÇÃO (Kgf) }\end{array}$ & $\begin{array}{c}\text { DESVIO PADRÃO DA } \\
\text { RESISTÊNCIA À TRAÇÃO } \\
\text { (Kgf) }\end{array}$ \\
\hline LH & 40 & 14,21 & 2,31 \\
\hline LH & 80 & 14,43 & 1,98 \\
\hline LED & 40 & 13,00 & 1,30 \\
\hline LED & 80 & 14,26 & 2,89 \\
\hline
\end{tabular}

Resina Cor A4 - Análise de Variância a 2 critérios:

\begin{tabular}{|c|c|c|c|c|c|c|}
\hline Efeito & gl efeito & qm efeito & gl erro & qm erro & $\mathrm{F}$ & $\mathrm{P}=$ \\
\hline Aparelho & 1 & 4,795562 & 36 & 4,806213 & 0,997784 & 0,324514 \\
\hline Tempo & 1 & 5,498222 & 36 & 4,806213 & 1,143982 & 0,291932 \\
\hline Interação & 1 & 2,740522 & 36 & 4,806213 & 0,570204 & 0,455090 \\
\hline
\end{tabular}

$\mathrm{Ns}=$ diferença estatisticamente não significante $(\mathrm{p}>0,05)$ 


\section{ANEXO III}

Gráfico com análise estatística Resina A1

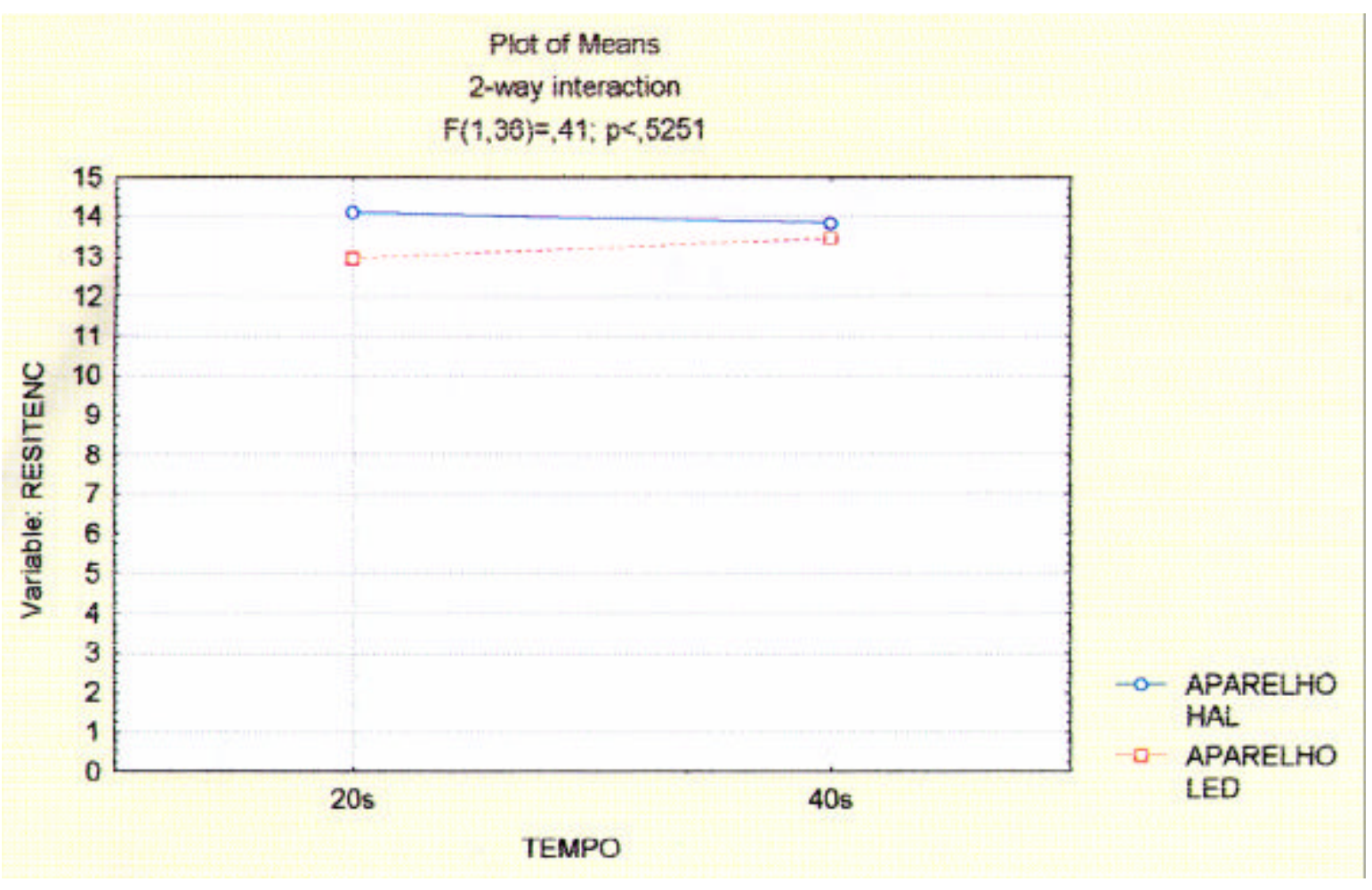




\section{ANEXO IV}

Gráfico com análise estatística Resina A4

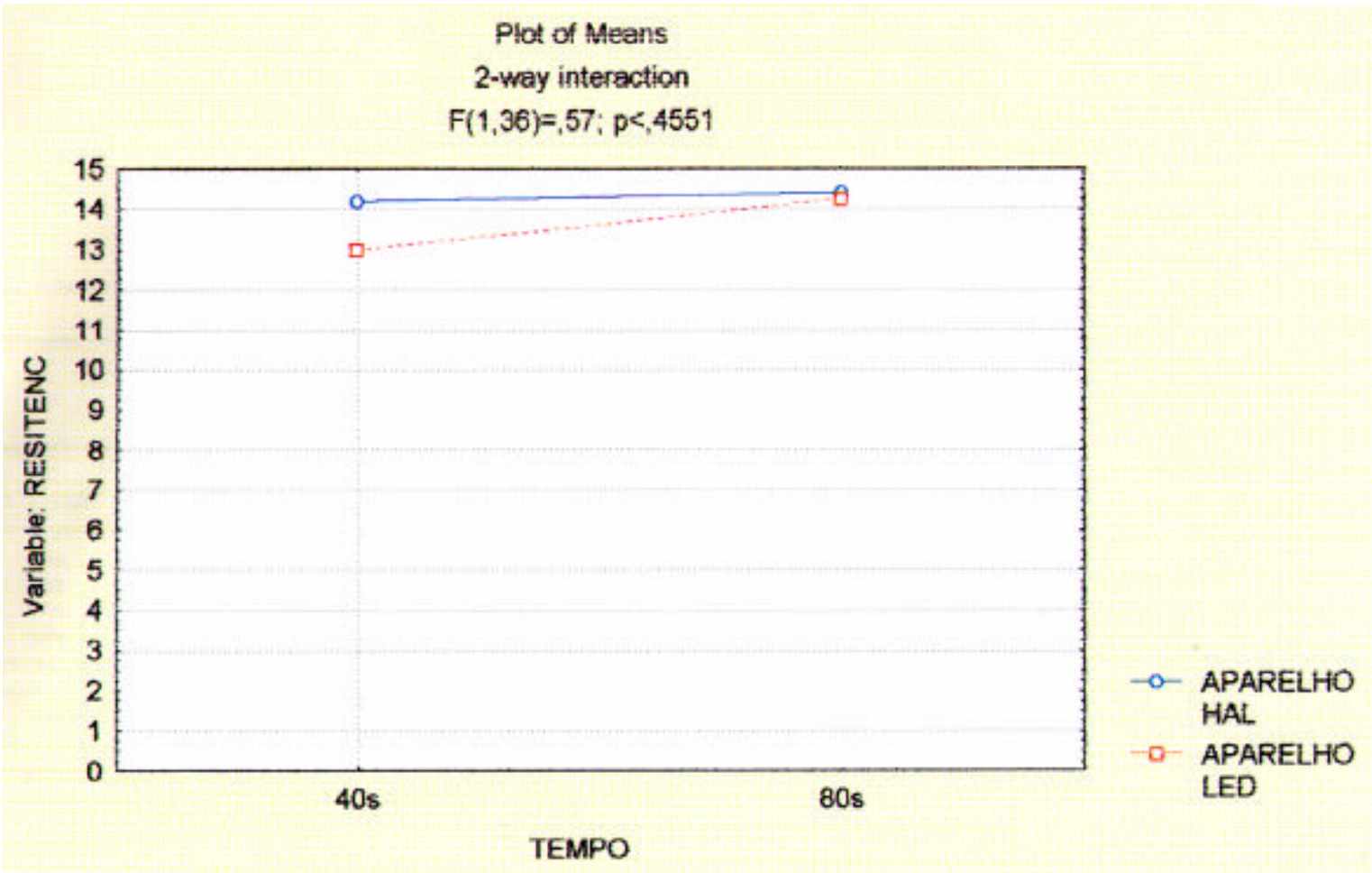




\section{ANEXO V}

Diagrama adaptado de SHORTALL; HARRINGTON ${ }^{65}$

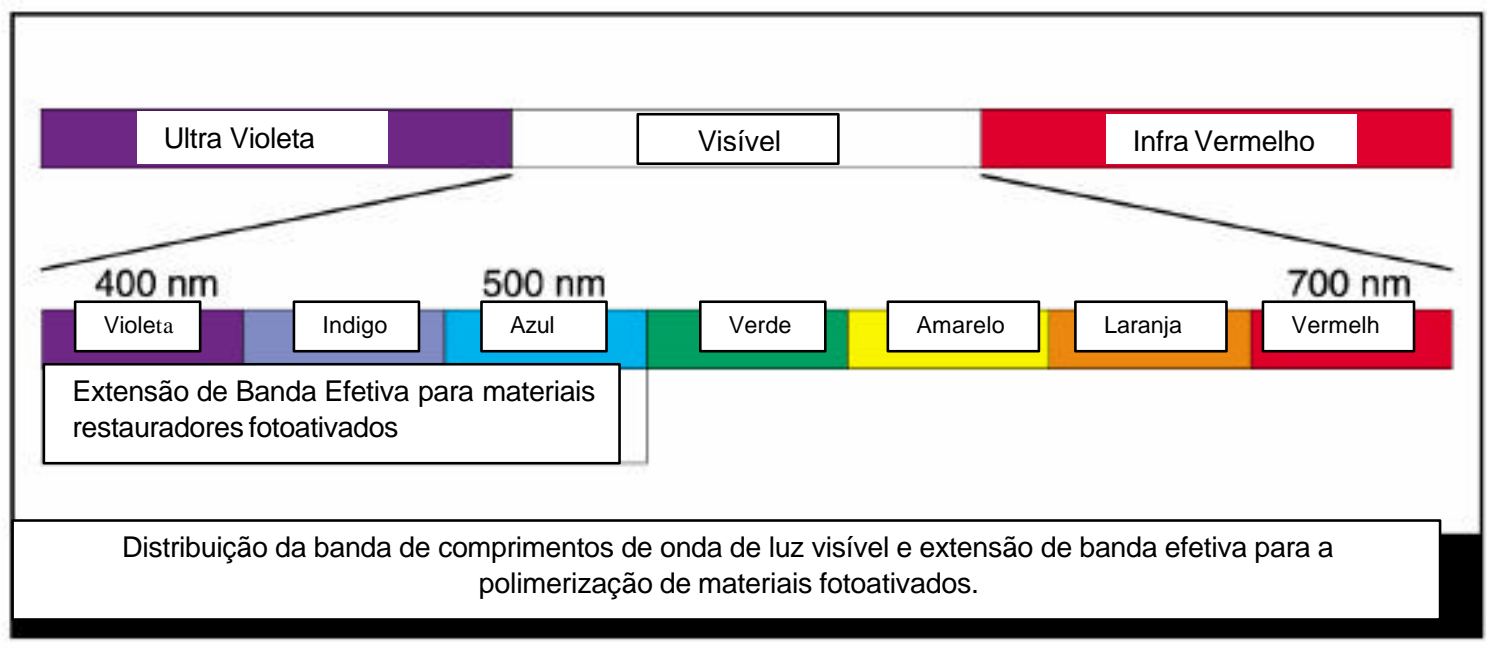


REFERÊNCIAS BIBLIOGRÁFICAS 


\section{REFERÊNCIAS BIBLIOGRÁfICAS}

1. ARAÚJO, R.M.; ARAÚJO, M.A.M.; FERNANDES, R.V.B. Efeito da intensidade de luz e irradiação de calor de fotopolimerizadores em função do tempo de uso. J. bras. Odont. Clin., v.1, n.6, p.50-5, nov./dez.1997.

2. ASMUSSEN, E. Restorative resins: hardness and strength vs quantity of remaining double bonds. Scand. J. dent. Res., v.90, n.6, p.484-9, Dec. 1982.

3. BARGHI, N.; BERRY, T.; HATTON, C. Evaluating intensity output of curing lights in private dental offices. J. Amer. dent. Ass. v.125, n.7, p.992-6, July 1994.

4. BOSQUIROLI, V.; FRANCO, E.B.; LOPES, L.G. Avaliação da resistência à tração de um cimento ionomérico modificado por resina em função do tipo de luz. Pesq. Odont. bras., v.16, p.241, 2002. /Resumo n. Pc210/.

5. BURTSCHER, P.; RHEINBERGER, V. Efficiency of LED Lights in comparison to halogen lamps. J. Dent. Res., v.81, p. A-486, Mar. 2002. Special Issue /Abstract 3975/.

6. CAUGHMAN, W.F.; RUEGGEBERG, F.A.; CURTIS JR.; J.W.; Clinical Guidelines for Photocuring restorative resins. J. Amer. Dent. Ass., v.126, n.9, p.1280-6, Sep 1995.

7. CAUGHMAN, W.F. et al. Correlation of cytotoxicity, filler loading and curing time of dental. composites. Biomaterials, v.12, n.8, p.737-40, Oct. 1991.

8. CHRISTENSEN, G. J. The curing light dilemma. J. Amer. Dent. Ass. v. 133, n.6, p. 761-3. June. 2002. 
9. COBB, D.S.; VARGAS, M.A.; RUNDLE, T. Physical properties of composites cured with conventional light or argon laser. Amer. J. Dent., v.9, n.5, p.199-202, Oct. 1996.

10.CORRÊA, I.C.; MUENCH, A.Y.; VALLESTER, R.Y. Resistência flexural de compósitos em função de dimensões e fotoativação. Pesq. Odont. bras., v.16, p.74. Suplemento 2000 /Resumo. A109/.

11. CRAIG, R.G. Restorative Dental Materials. 9. ed. St Louis, Mosby, 1993 p.248-82.

12. CURING Light 2500. Especificações do produto 3M do Brasil.

13.DE WALD, J.P.; FERRACANE, J.L. A comparisson of four modes of evaluating depth of cure of light-activated composites. J. dent. Res., v. 66, n.3, p.727-30, Mar. 1987.

14.DUNN, W.J.; VUSH, A.C. A comparison of polymerization by light-emitting diode and halogen-based light-curing units. J. Amer. dent. Ass., v.133, n.3, p.335-41, Mar. 2002.

15.FAN, P.L. et al. Irradiance of visible light-curing units and voltage variation effects. J. Amer. dent. Ass., v.115, n.3, p.442-5, Sept. 1987.

16.FAN, P.L. et al. Curing-light intensity and depth of cure of resin-based composites tested according to international standards. J. Amer. dent. Ass., v.133, n.4, p.429-34. Apr. 2002.

17.FAY, R.-M.; LU, H.; PWERS, J.M. Mechanical properties of composite cured with LED and QTH curing lights. J. dent. Res., v.81, p. A-85, Mar. 2002. /Abstract n. 0484/

18. FERRACANE, J. L. et al. Relationship between shade and depth of cure for light-activated dental composite resins. Dent. Mat., v.2, n.2, p.80-4, Apr. 1986.

19.FERRACANE, J.; MARKER, V.A. Solvent degradation and reduced fracture toughness in aged composite. J. dent. Res., v.71, n.1, p.13-9, 1992. 
20.FOWLER, C.S.; SWARTZ, M.L.; MOORE, B.K. Efficacy testing of visible-light curing units. Oper Dent., v.19, n.2, p.47-52. Mar./Apr. 1994.

21.FRANCO, E.B.; NAVARRO, M.F.L. Avaliação do comportamento do sistema de polimerização por luz emitida por diodo, LED, em comparação ao sistema de luz halógena. Bauru, FOB-USP, 2002.

22. FRANCO, E.B. et al. Avaliação da profundidade de polimerização e dureza de resinas compostas fotopolimerizáveis com e sem a interferência do esmalte dentário. Rev. bras. Odont., v. 48I. n.1, jan./fev. 1991.

23. FREITAS, A. P. et al. Estrutura e propriedades mecânicas dos materiais. /Apresentado em seminário, na disciplina BAM 5708 do Mestrado em Odontologia, concentração Materiais Dentários. Faculdade de Odontologia de Bauru, Universidade de São Paulo, 2001/

24.FUJIBAYASHI, K.; ISHIMARU, K.; TAKAHASHI, N.; KAHNO,A. Newly developed curing unit using blue light-emitting diodes. Dent. Jpn., v.34, p. 49-53, 1998.

25. GAUDET, S.; BURGESS, J.O.; LSUHSC, L.L.I. Depth of cure of three composites cured with three curing lights at three times. J. dent. Res., v.81, p.A-85 Mar. 2002. Special Issue A. /Abstract n. 0482/.

26. HANSEN, E.K.; ASMUSSEN, E. Correlation between depth of cure and surface hardness of a light-activated resin. Scand. J. dent. Res., v.101, n.1, p.62-4, Feb. 1993.

27.HARRINGTON, E.; WILSON, H.J.; SHORTALL, A.C. Light-activated restorative materials: a method of determining effective radiation times. $\mathbf{J}$. oral. Rehab., v.23, n.3, p.210-8, Mar. 1996.

28. HIRABAYASHI, S. Improvements to light transmittance in light-cured composite resins by the utilization of low refractive index dimethacrylates. Dent. Mater., v.9, n.2, p.203-14, Dec. 1990. 
29. JANA, B.C.; SANTOS, M.; CORRÊA. Influência da fotoativação por LED e luz halógena na resistência flexural de várias resinas compostas. Pesq. Odont. bras., v.16, p.106, 2002. Suplemento /Resumo. Ic132.

30.JANDT, K.D. et al. Depth of cure and compressive strength of dental composites cured with blue light emitting diodes (LEDs). Dent. Mat., v.16, n.1, p.41-7, Jan. 2000.

31.KNEZEVIC, A. et al. Degree of conversion and temperature rise during polymerization of composite resin samples with blue diodes. J. Oral. Rehab., v.28, n.6, p.586-91, June 2001.

32. KURACHI, C. et al. O uso de LED'S na polimerização da resina composta dental: proposta e avaliação da eficiência de um dispositivo elaborado. Pesq. Odont. bras., v.16, p.119, 2000. Suplemento /Resumo B090/.

33.KURACHI, C. et al. Hardness evaluation of a dental composite polymerized with experimental LED- based devices. Dent. Mat., v.17, n.4, p.309-15, July 2001.

34.LEONARD, D.L.; CHARLTON, D.G.; HILTON, T.J. Effect of Curing-tip diameter on the accuracy of dental radiometers. Oper. Dent., v.24, n.1, p.31-7, Jan./Feb. 1999.

35. LOPES, G.C. et al. Resistência á compressão diametral de resinas compostas fotopolimerizadas com um novo aparelho LED. Pesq. Odont. bras., v.16, p.78, 2002. Suplemento /Resumo lb142/

36.LOVELL, L.G.; NEWMAN, S.M.; BOWMAN, C.N. The effects of light intensity, temperature, and comonomer composition on the polymerization behavior of dimethacrylate dental resins. J. dent. Res., v.78, n.8, p.146976, Aug. 1999.

37.MANDARINO, F.; PORTO. C.L. de A. Microdureza das resinas compostas fotoativadas em diferentes profundidades de polimerização: efeito de fontes de luz e materiais. Rev. bras. Odont., v.37, n.4, p.314-8, jul./ago. 1989. 
38. MC CABE, J.F.; CARRICK, T.E. Output from visible-lingt activation units and depth of cure of light-activated composites. J. dent. Res., v.68, n.11, p.1534-9, Nov. 1989.

39.MEDEIROS, I.S. Dispositivos LED para polimerização de resinas compostas dentais: comparação com outras fontes de luz. Dissertação (Mestrado) - São Carlos, 2001. 113p. Interunidades em Ciências e Engenharia de Materiais. Escola de Engenharia de São Carlos, Instituto de Física de São Carlos, Instituto de Química de São Carlos. São Carlos. Universidade de São Paulo.

40.MILLS, R.W. Blue light emitting diodes: another method of light curing. Brit. dent. J., v.178, n.5. p.169, Mar. 1995.

41. MILLS, R.W.; JANDT, K.D.; ASHWORTH, S.H. Dental composite depth of cure with halogens and blue light emitting diode technology. Brit. dent. J. v.186, n.8.p.388-91, Apr. 1999.

42. MITTON, B.A.; WILSON, N.H.F. The use and maintenance of visible light activating units in general practice. Brit. dent. J., v.191, n.2, p.82-6, July 2001.

43. MIYAZAKI, M. et al. Effect of light exposure on fracture toughness and flexural strength for light-cured composites. Dent. Mater., v.12, n.6, p.328-32, Nov. 1996.

44.MOORE, B.K.; PLATT, H.E.; DUKE,E.S. Properties of three commercial LED, blue-light activating units. J. dent. Res., v.81, p. A-486 Mar. 2002 Special Issue A. /Abstract 3977/.

45. NAGEM FILHO, H. Materiais dentários: resinas compostas. 2.ed. Bauru, Produções Artes Gráficas, 2000.

46. NAKAMURA, S.; SENOH, M.; IWASA, N.NAGAHAMA, S. High-power InGaN single-quantum-well-structure blue and violet light-emitting-diodes. Appl. Phys. Lett., v.67, n.13 p. 1868-70, 1995. 
47. NICHOLLS, J.I. Dental lights, light meters, and light meter readings: practically speaking. Quintessence Int., v.32, n.10, p.818-9, Nov./Dec. 2001.

48. NOMOTO, R. Effect of light wavelength on polymerization of light-cured resins. Dent. Mat., v.16, n.1, p.60-73, 1997.

49. NOMURA.Y. et al. Thermal analysis of dental esins cured with blue lightemitting diodes (LEDs). J. Biomed. Mat. Res., v.63, n.2, p.209-13. Jan. 2002

50.PALMER, T.M. et al. Light emitting diode resin polymerization compare to three other methods. J. dent. Res., v.81, p.A-486 Mar. 2002. Special Issue A. /Abstract n. 3976/.

51.PARK, Y.J.; CHAE, K.H.; RAWLS, H.R. Development of a new photoinitiation system for dental light-cure composite resins. Dent. Mat., v.15, n.1, p.120-27, Jan./Feb. 1999.

52.PARK, S.H.; KREFCI, I.; LUTZ, F. Microhardness of resin composites polymerized by plasma arc or conventional visible light curing. Oper. Dent., v.27, n.1, p.30-7/12-8/5-11, Jan./Feb. 2002.

53.PEREIRA, S.K. Resina composta fotopolimerizável: avaliação da dureza superficial em função de cor, tempo de exposição, intensidade de luz e profundidade do material. Araraquara, 1999. 216p. Tese (Doutorado) Faculdade de Odontologia, Universidade Estadual Paulista.

54.PFEIFER, S.; FRIEDL, K.-H; HILLER, A.S.; SCHMALZ, G. Efficiency of LED and halogen polymerization in composite restorations. J. dent. Res., v.81, p.A-486 Mar. 2002. Special Issue A. /Abstract 3974/..

55.PIMENTEL, K.L. et al. LED versus luz halógena: efeito na espessura de polimerizações da resina composta. Pesq. Odont. bras., v.16, p.77, 2002 /Resumo n.lb129/

56. RUEGGEBERG, F. Contemporary Issues in photocuring. Compendium, v.20, p.4-5, Nov. 1999. Suplemento 25. 
57.RUEGGEBERG, F.A.; CAUGHMAN, W.F.; CURTIS JR, J.W. Effect of light intensity and exposure duration on cure of resin composite. Oper. Dent., v.19, n.1, p.26-32, Jan./Feb. 1994.

58.SAKAGUSHI, R.L.; DOUGLAS, W.H.; PETERS, M.C.; Curing light performance and polymerization of composite retorative materials. $\mathbf{J}$. Dent., v.20, p.183-8, 1992.

59.SANTOS JR., G.C.; EL-MOWAFY, O.; RUBO, J.H. Dureza de um cimento resinoso dual: efeito da intensidade e do tipo de fonte de luz. Pesq. bras. Odont., v.16, p.16. Suplemento 2002. /Resumo n. H013/.

60.SANTOS, L.A. et al. Microdureza de resina composta: efeito de aparelhos e tempos de polimerização em diferentes profundidades. Pesq. Odont. bras., v.14, n.1, p.65-70, jan./mar. 2000.

61.SEABRA, B. G. de M. Avaliação da profundidade de polimerização de resinas compostas "condensáveis" em função do tempo de exposição à luz e da interferência do esmalte dentário. Bauru, 2000. 96p. Dissertação (Mestrado) - Faculdade de Odontologia de Bauru, Universidade de São Paulo.

62.SHIN, M.A.; DRUMMOND, J.L. Evaluation of chemical and mechanical properties of dental composites. J. Biomed. Mat Res., v.48, n.4, p.540-5, 1999.

63.SHORTALL, A.C.; HARRINGTON, E. Effect of light intensity on polymerisation of three composite resins. Europ. J. Prosthodont. Restorat. Dent., v.4, n.2, p.71-6, June 1996.

64.SHORTALL, A.C.; UCTASLI, S.; MARQUIS, P.M. Fracture resistance of anterior, posterior and universal light activated composite restoratives. Oper. Dent., v.26, n.1,. p.87-96, Jan./Feb 2001.

65.SHORTALL, A.; HARRINGTON, E. Guidelines for the selection, use, and maintenance of visible light activation units. Brit. dent. J., v.181, n.10, p.383-7, Nov. 1996. 
66. SOLDERHOLM, K.J. Degradation of glass filler in experimental composites. J. dent. Res., v.60, n.11, p.1867-73, Nov 1981.

67.STAHL, F. et al. Light-emitting diode (LED) polymerisation of dental composites: flexural properties and polymerization potential. Biomaterials., v.21, n.13, p.1379-85, July 2000.

68.SUH, B.I. Controlling and understanding the polymerization shrinkage induced stresses in light cured composites. Compendium, v.20, p.34-41,. Nov. 1999. Suplemento 25.

69.SWARTZ, M.L.; PHILLIPS, R.W.; RHODES, B. Visible light-activated resins: depth of cure. J. Amer. dent. Ass., v.106, n.5, p.634-7, May 1993.

70.TAKAHASHI, K.; FUJIBAYASHI, K. Newly developed light-activate units using blue-light-diodes. Part two: effects of spectral distribution of SQW - LED on the polymerization of resin composite Jpn J. consej. Dent. v.41, p.509-16, 1998.

71.TAIRA, M. et al. Analysis of photo-initiators in visible-light-cured dental composite resins. J.dent. Res., v.67, n.1, p.24-8, Jan. 1988.

72.TOLOSA, M.C.C.G. et al. Influência da fonte ativadora do compósito odontológico na resistência à tração diametral. Pesp. Odont. Bras., v.16, p.55, 2002. /Resumo n.la182/.

73.TONIOLI, M. et al. Depht of cure comparison of LED, plasma Arc, and QTH curing lights. J. Dental. Res., v.81, p. A-86, 2002. Special Issue. /Abstract n.0490/.

74. ULTRALED Dabi Atlante. Especificações do Aparelho. Produto Dabi Atlante.

75.VARGAS, M.A.; COBB, D.S.; SCHMIT. J.L. Polymerization of composite resins: argon laser vs conventional light. Oper. Dent., v.23, n.2, p.87-93, Mar. 1998.

76. VELASCO, G.G.; JOÃO, M.; CORRÊA, I.C. Análise do monômero residual em uma resina com diferentes sistemas canforoquinona/amina ativada por 
LED e luz halógena. Pesp. Odont. bras., v.16, p.103, 2002. /Resumo n. Ic108/.

77.VIEIRA, L.C.C.; BERNARDON, J.K.; LOPES,G.C. Avaliação da profundidade de cura de resinas compostas micro-híbridas com dois aparelhos fotopolimerizadores: luz halógena e LED. Pesp. Odont. bras., v.16, p.108, 2002. /Resumo n. 147/.

78. VINHA, D. et al. Análise da profundidade de polimerização de resinas compostas polimerizadas por luz halógena e luz de emissão de diodo. Pesp. Odont. Bras., v.16, p.155, 2002. /Resumo n. Pa 262/.

79.YAP, A.U.J.; SENEVIRATNE, C. Influence of light energy density on effectiveness of composite cure. Oper. Dent., v.26, n.6, p.460-6, June 2001

80. YEARN, J.A.; MACCLESFIELD, UK. Factors affecting cure of visible light activated composites. Int. dent. J., v.35, n.3, p.218-5, Sept. 1985.

81.WHATATE.; PORTER, K.H.; DOSCH, R.O. Successful photocuring: don't restore without it. Oper. Dent., v.24, n.2, p.109-14, Mar./Apr. 1999. 
Abstract 


\section{ABSTRACT}

\section{Evaluation of tensile strength of a photo polymerizing resin composite, as related to different sources of light and activation times.}

The aim of this study was to evaluate the tensile strength of the composite resin by different light units and different activation times. So, a conventional light curing unit, Curing Light 2500- 3M $\left(670 \mathrm{mw} / \mathrm{cm}^{2}\right)$ and another LED type (light emitting diode) Ultraled Dabi Atlante $\left(130 \mathrm{mw} / \mathrm{cm}^{2}\right)$ were used. To obtain the specimens a set of stainless matrix composed by two parts was used, each one presenting a conic central orifice measuring $6.0 \mathrm{~mm}$ of smaller diameter and $8.0 \mathrm{~mm}$ of larger diameter with $1.0 \mathrm{~mm}$ in depth. The composite resin utilized was the Z250-3M in A1 and A4 shades. Eight groups with ten specimens each were made; four of which polymerized with halogen light cure and the other four with LED. For the halogen light cure unit, two groups with the Z250 A1 shade, with the respective cure times of $20 \mathrm{~s}(\mathrm{G} 1)$ and $40 \mathrm{~s}(\mathrm{G} 2)$ and two groups with $\mathrm{A} 4$ shade, with cure times of $40 \mathrm{~s}$ (G3) and $80 \mathrm{~s}$ (G4) were used. The same was done with the LED groups: two groups with the Z-250 shade A1, with $20 \mathrm{~s}$ (G5) and $40 \mathrm{~s}$ (G6) and two groups with shade $A 4$, with cure times of 40 s (G7) and 80 s (G8) respectively. Ten minutes after obtaining the specimens the set was adapted to a special device to allow for adaptation at the universal testing machine and then the tensile test was done at a cross speed of $0,5 \mathrm{~mm} / \mathrm{min}$. The obtained values were submitted to a two-way variation ANOVA analysis. The means and standard deviation were respectively: G1 - 14,13 $\pm 2,03$; G2 - 13,85 $\pm 2,46$; G3 - 14,21 $\pm 2,31$; G4 - 14,42 \pm 1,97; G5 - 12, $95 \pm 1,09$; G6 - 13,46 $\pm 2,02 ;$ G7 - 12,99 $\pm 1,29 ;$ G8 - 14, $25 \pm 2,89$. It is concluded that: (1) The LED photo polymerizing unit was as effective for the polymerization of resin composite as the halogen light unit. (2) The increase in polymerization time did not exert an influence on the resin composite tensile strengths, no matter what kind of light source was used nor the material color. (3) The tensile strength for the $Z 250$ resin, colors $A 1$ and $A 4$, was not affected by the activation time variation nor the sources of halogen and LED lights. 